\title{
Validation of the ICRF antenna coupling code RAPLICASOL against TOPICA and experiments
}

\author{
W. Tierens ${ }^{1}$, D. Milanesio ${ }^{2}$, G. Urbanczyk ${ }^{3,4}$, W. Helou ${ }^{4}$, \\ V. Bobkov ${ }^{1}$, J.-M. Noterdaeme ${ }^{1,5}$, L. Colas ${ }^{4}$, R. Maggiora ${ }^{2}$, \\ the ASDEX Upgrade Team ${ }^{6}$, the EUROfusion MST1 \\ Team $^{7}$ \\ ${ }^{1}$ Max-Planck-Institut für Plasmaphysik, Garching, Germany \\ 2 Politecnico di Torino, Dipartimento di Elettronica, Torino, Italy \\ 3 Institute of Plasma Physics, Chinese Academy of Sciences, Hefei, P. R. China \\ ${ }^{4}$ CEA, IRFM, F-13108 Saint-Paul-Lez-Durance, France \\ ${ }^{5}$ Ghent University, Applied Physics Department, Gent, Belgium \\ 6 See A. Kallenbach et al., Nucl Fusion 57 (2017) 102015 \\ 7 See H. Meyer et al., Nucl Fusion 57 (2017) 102014 \\ E-mail: wtt@ipp.mpg.de \\ August 2018
}

\begin{abstract}
In this paper we validate the Finite Element code RAPLICASOL, which models radiofrequency wave propagation in edge plasmas near ICRF antennas, against calculations with the TOPICA code. We compare the output of both codes for the ASDEX Upgrade 2-strap antenna, and for a 4-strap WESTlike antenna. Although RAPLICASOL requires considerably fewer computational resources than TOPICA, we find that the predicted quantities of experimental interest (including reflection coefficients, coupling resistances, S- and Z-matrix entries, optimal matching settings, and even radiofrequency electric fields) are in good agreement provided we are careful to use the same geometry in both codes.
\end{abstract}




\section{Introduction}

Understanding the behaviour of radiofrequency ( $\mathrm{RF}$ ) waves in tokamak edge plasmas is of paramount importance since ICRF (Ion Cyclotron Range of Frequencies) antennas are needed for heating and current drive. Several codes to model the wave behaviour have been developed, notably TOPICA (TOrino Polytechnic Ion Cyclotron Antenna [1-4]), RAPLICASOL (based on COMSOL [5]) and more recently ERMES 6 (open-source). RAPLICASOL (Radiofrequency wAve couPLing for Ion Cyclotron Antenna in Scrape-Off-Layer [7]) is a Finite Element approach to this problem. Although it has been used successfully to predict the influence of gas puffing on the coupling resistance 8 , it has not thus far been validated as thoroughly as TOPICA, which is the goal of this paper.

This paper is organized as follows: in section 2 we introduce the RAPLICASOL code. In section 3. we briefly introduce the TOPICA code. It is not the goal of this paper to discuss TOPICA in detail, but we do need to stress just how different both approaches are. Section 4 contain comparisons between RAPLICASOL, TOPICA, and RF measurements during experiments, for the ASDEX Upgrade 2-strap antenna. Section 5 contains similar comparisons for a WEST-like antenna. The conclusion is in section 6 .

\section{RAPLICASOL}

RAPLICASOL [7 is a program based on the commercial software COMSOL [5]. COMSOL provides the capability of solving Maxwell's equations in frequency domain using Finite Elements. RAPLICASOL adds to this the Stix tensor (1), Perfectly Matched Layers ( [9], section 2.3), and parametrized antennas (section 2.1). For earlier work on using COMSOL for ICRF antennas, see 10.

RAPLICASOL was not originally intended to be a standalone RF code, but rather to be the RF module of the nonlinear sheath code SSWICH 11, 12. As we extended the capabilites of both RAPLICASOL and SSWICH, it became apparent that RAPLICASOL has its own uses independent from SSWICH, such as the calculation of coupling resistances when the plasma is not toroidally and poloidally uniform 8,13.

RAPLICASOL uses a Finite-Element approach in which the vacuum and plasma volumes near the antenna are meshed with tetrahedral elements. On this mesh, Maxwell's equations in the cold plasma approximation in the frequency domain (i.e. with dielectric tensor given by (1) in the Stix frame [14, and density profile and background magnetic field assumed known) reduce to a large system of linear equations,

\begin{tabular}{l|r} 
Geometry & Number of parameters \\
\hline antenna box & 28 \\
coaxial lines & 12 \\
folded straps & 58 \\
Faraday screen & 9 \\
limiter tiles & 62 \\
PSL & 5
\end{tabular}

Table 1. Overview of the RAPLICASOL geometry parameters.

which is solved iteratively.

$\varepsilon=1-\sum_{\mathrm{p}}\left[\begin{array}{ccc}\frac{\omega_{p}^{2}}{\omega^{2}-\Omega_{p}^{2}} & \left(\frac{\Omega_{p}}{-i \omega}\right) \frac{\omega_{p}^{2}}{\omega^{2}-\Omega_{p}^{2}} & 0 \\ \left(\frac{\Omega_{p}}{i \omega}\right) \frac{\omega_{p}^{2}}{\omega^{2}-\Omega_{p}^{2}} & \frac{\omega_{p}^{2}}{\omega^{2}-\Omega_{p}^{2}} & 0 \\ 0 & 0 & \frac{\omega_{p}^{2}}{\omega^{2}}\end{array}\right]$

$\omega=$ radial antenna frequency

$\omega_{p}=$ radial plasma frequency of specie $p$

$\Omega_{p}=$ radial cyclotron frequency of specie $p$

The Finite Element formulation makes it relatively straightforward to impose fully non-uniform plasma parameters, including arbitrary 3D density profiles and background magnetic fields 8,13 , while the plasma module in TOPICA, FELICE, is limited to 1D (radial) variation of the plasma parameters.

\subsection{Parametrized geometry}

By default, RAPLICASOL uses a fully parametrized antenna geometry. It is procedurally generated from about 170 numerical parameters which are summarized in table 1 and figure 1. This geometry, with default parameters, is shown in figure 2 RAPLICASOL does not presently take the tokamak curvature into account: the antenna geometry is flat. This is due in part to the difficulty of procedurally constructing the curved geometry, and in part to the difficulty of constructing an absorbing boundary layer (PML) in a curved geometry 9]. The default geometry includes the Passive Stabilizing Loops (PSL) above and below the antenna. The PSLs are intended to reduce the growth rate of certain MHD instabilities. They are included in the RAPLICASOL geometry because of their possible influence on the parallel electric field (and thus on sheath formation) near the top and the bottom of the antenna.

\subsection{Imported geometry}

RAPLICASOL is also able to import (sufficiently simple) CAD geometries. Two geometries in this paper are imported, as opposed to being procedurally constructed: the "RAPLICASOL imported flat" 

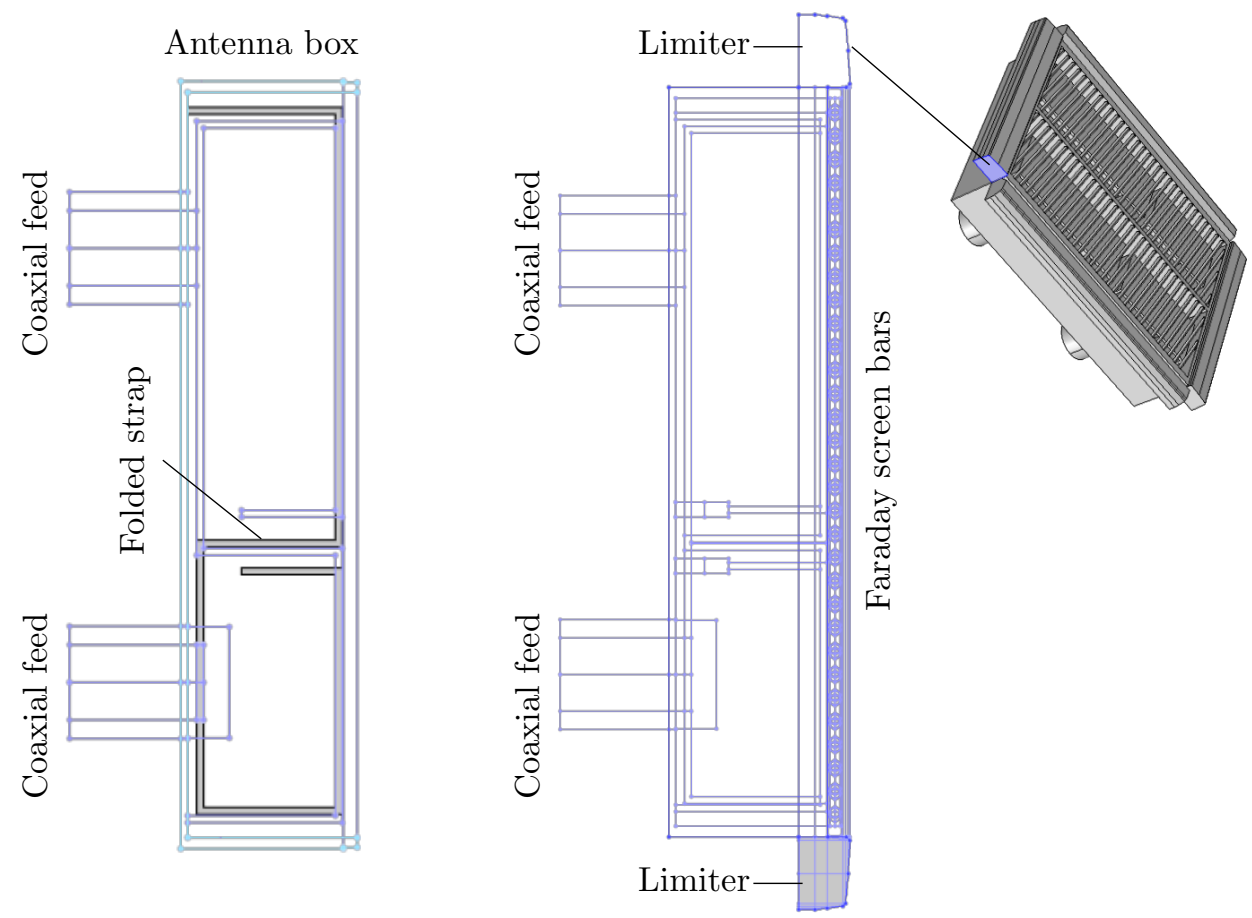

Figure 1. Intermediate stages (not all parts of the geometry are present at this stage) in the procedural construction of the RAPLICASOL model of the ASDEX Upgrade 2-strap antenna. $70 \%$ of the geometry parameters specify the coordinates of the folded straps (left) and the limiter cross sections (right).
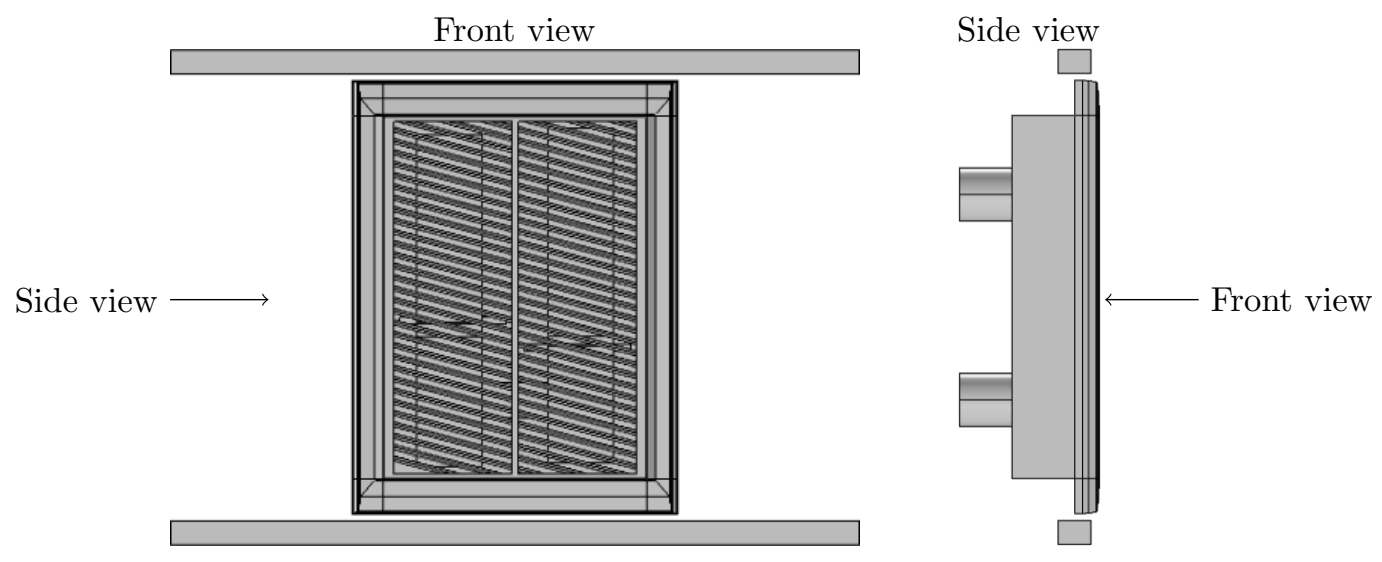

Figure 2. Complete RAPLICASOL 2-strap antenna geometry, front and side view. The horizontal bars above and below the antenna are the Passive Stabilizing Loops (PSL). In reality the PSLs are larger.

geometry in section 4.1, and the WEST-like geometry in section 5 .

\subsection{Boundary conditions}

In RAPLICASOL, as in TOPICA, the antenna is assumed to be a perfect conductor.

RAPLICASOL does not model the core plasma (unlike 15,16): the simulation region is terminated on all but one side by an absorbing layer, a socalled Perfectly Matched Layer or PML [9]. The remaining side is the tokamak wall, where there is a perfectly conducting boundary condition (Perfect Electric Conductor "PEC" wall).

\section{RAPLICASOL and TOPICA}

TOPICA [1,2], like RAPLICASOL, models ICRF wave propagation in the edge plasma near the antenna, but the computational/mathematical approach of this code is very different. TOPICA uses surface meshing and a method of moments approach to calculate the fields in vacuum near the antenna, and a full hot plasma code (FELICE) for the plasma even in the edge (see table 


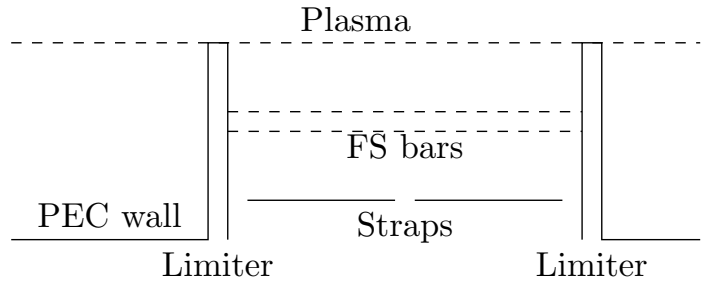

Figure 3. Limiters can protrude into the tokamak vessel in RAPLICASOL

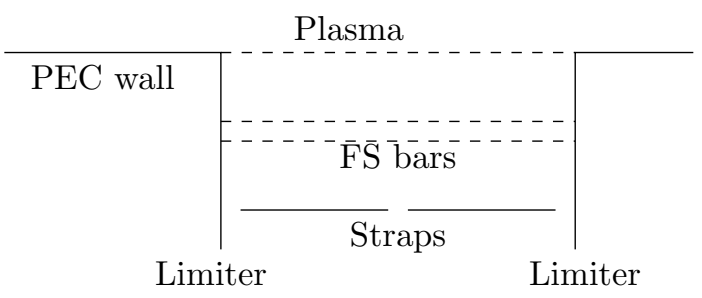

Figure 4. The antenna is entirely recessed in TOPICA

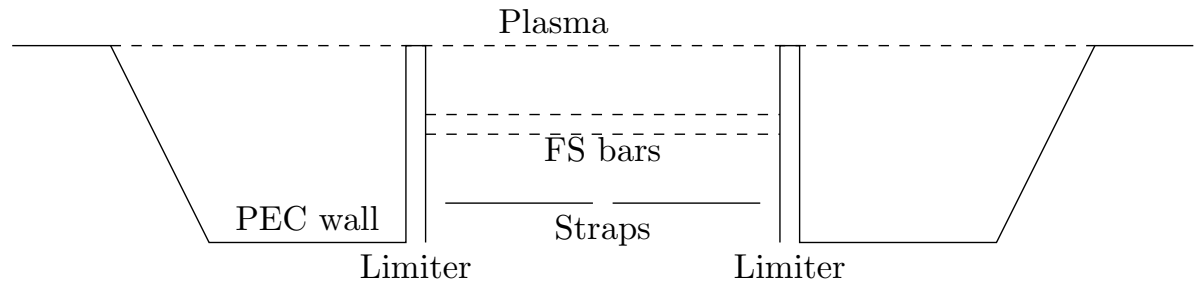

Figure 5. Protruding parts can be approximated in TOPICA only by extending the cavity in which the entire geometry is recessed

\begin{tabular}{|c|c|c|}
\hline & RAPLICASOL & TOPICA \\
\hline Geometry & $\begin{array}{l}\text { flat } \\
\text { possibly protruding }\end{array}$ & $\begin{array}{l}\text { flat or curved } \\
\text { recessed }\end{array}$ \\
\hline Vacuum & $\begin{array}{l}\text { tetrahedral volume mesh } \\
\text { Finite Element (FE) solution }\end{array}$ & $\begin{array}{l}\text { triangular surface mesh } \\
\text { Method of Moments (MoM) }\end{array}$ \\
\hline Plasma & $\begin{array}{l}3 \mathrm{D} \text { Cold plasma } \\
\text { tetrahedral volume mesh } \\
\text { Finite Element solution }\end{array}$ & $\begin{array}{l}\text { 1D hot plasma } \\
\text { FELICE }\end{array}$ \\
\hline Termination & Perfectly Matched Layer (PML) & $\begin{array}{l}\text { Outward boundary condition in FELICE } \\
\text { (effectively an absorbing boundary condition) }\end{array}$ \\
\hline CPU usage & $\begin{array}{l}\text { For AUG 2-strap antenna: } \\
32 \text { CPUs for } 3 \text { hours } \\
\text { Workstation with } 256 \mathrm{~GB} \text { RAM }\end{array}$ & $\begin{array}{l}\text { For AUG 2-strap antenna: } \\
576 \text { CPUs for } 5 \text { hours } \\
\text { High-performance computing }\end{array}$ \\
\hline
\end{tabular}

Table 2. Comparison between RAPLICASOL and TOPICA.

2).

In addition to the computational differences, there is also a geometric difference. In the default parametrized RAPLICASOL geometry, and in reality, the antenna limiters protrude into the vessel (figure 3. Due to the way TOPICA imposes field continuity between the vacuum and the plasma region, the entire TOPICA antenna must be bounded in a cavity which is recessed in the vessel wall, i.e. the antenna limiters cannot protrude (figure 4. Protruding parts can be approximated in TOPICA only by extending the cavity itself to include also a portion of the first wall (figure 5 .

A typical RAPLICASOL calculation runs in about 3 hours on a workstation with $323.4 \mathrm{GHz}$ processors and $256 \mathrm{~GB}$ of RAM (though the runtime depends on tolerance settings for the iterative solver). A typical TOPICA calculation requires $576 \mathrm{CPUs}$ for 5 hours on the Marconi supercomputer 17].

3.1. The Lower Hybrid resonance, and the possibility of nonzero density in the antenna

Both RAPLICASOL and TOPICA modify the density profile in a non-physical way to avoid the Lower Hybrid (LH) resonance, a resonance which is notoriously difficult to handle with Finite Element approaches [18]. The density is modified either by introducing a sudden drop to vacuum (RAPLICASOL, figure 6 left) or by keeping the density above a certain minimum level and then suddenly dropping to vacuum (TOPICA, figure 6 right). In TOPICA, the antenna part must be in vacuum, since the surface meshing / Method of Moments approach requires knowledge of the Green's function. In Finite Element approaches such as RAPLICASOL, it should in principle be possible to have nonzero density in the antenna, but in practice 
this tends to cause convergence issues (currently in development is an upgraded version of ERMES [6], a Finite Element code whose "regularized" formulation may improve convergence in these conditions).
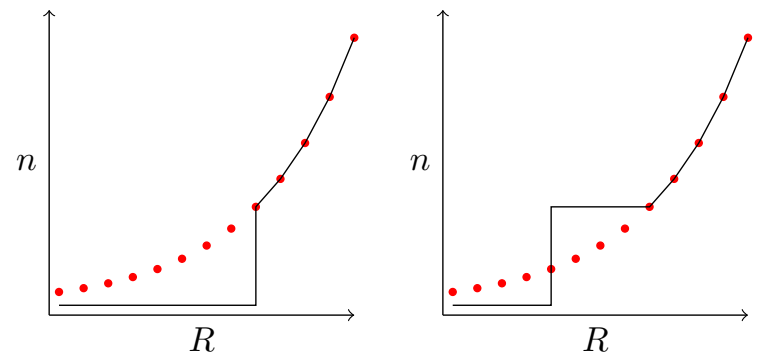

Figure 6. Density modification to avoid the LH resonance. Left: a sudden drop to vacuum in RAPLICASOL. Right: a sudden drop to vacuum and an imposed minimum density in TOPICA.

\subsection{Computational requirements}

3.2.1. TOPICA: While referring the interested reader to 2 for the detailed description of the TOPICA code architecture (in particular section 4.1 where the full algebraic system is reported and discussed), we would like to herein recall some basic ideas. The full interaction matrix is a $(N+M) \times(N+$ $M$ ) dense system, where $N$ and $M$ are the number of electric and magnetic unknowns respectively. To provide numbers, for the flat TOPICA model of the AUG 2-strap antenna, $N$ is about $180 \cdot 10^{3}$ and $M$ is about $5 \cdot 10^{3}$, hence approximately 34 billion nonzero matrix entries need to be computed. Despite being a lot smaller than the remaining part of the full interaction system, the $M \times M$ subset is definitely the most time consuming portion of the code. This is due to the fact that this contribution, namely the interaction with plasma, has to be computed in the spectral domain where the spatially localized basisfunctions ("RWG" functions, a type of basis-functions defined on triangles, named after the authors of [19]) have an infinite domain and require a non trivial adaptive integration. Furthermore, the integrand function itself possesses singularities that should be properly tackled. To provide again some numbers, while the interaction between two cells is evaluated on about 250 samples in the spatial domain $(N \times N$ and $N \times M$ subsets), more than $75 \cdot 10^{3}$ sampling points are necessary in the spectral domain ( $M \times M$ subset). Once constructed, the system is solved through a standard inversion performed by the LAPACK library 20] (ZGETRF and ZTEGRS subroutines); system inversion computing time is small with respect to the computing of the vacuum-plasma interaction integrals.

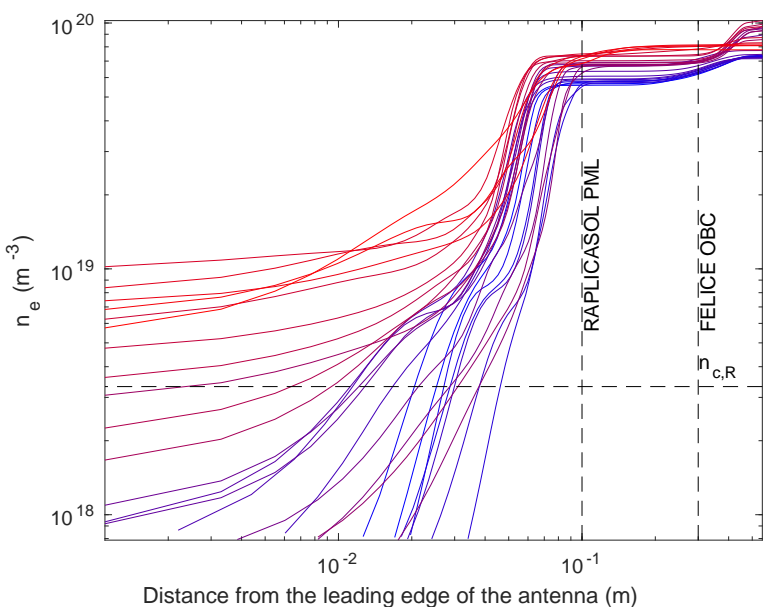

Figure 7. 27 consecutive density profiles, measured once every $0.2 \mathrm{~s}$ during a triangularity scan (ASDEX Upgrade shot \#29823). The color goes from blue (the first profile) to red (the last profile). The vertical dashed lines indicate where the simulation region terminates: at a Perfectly Matched Layer in RAPLICASOL, at an Outward Boundary Condition (OBC) in TOPICA (see table 2). Data beyond these lines is not used by RAPLICASOL resp. TOPICA. The horizontal dashed line is the R-cutoff density 24].

3.2.2. RAPLICASOL: In RAPLICASOL, on the other hand, calculating the sparse (due to the Finite Element approach) system of equations to be solved can be done in real space, and the calculation of the matrices takes a negligible fraction of the total runtime (on the order of minutes). The system is then solved iteratively using GMRES [21], with a multigrid preconditioner 22,23 .

The typical number of unknowns for our AUG simulations is $18 \cdot 10^{6}$ (for a total of $O(1) \cdot 18$. $10^{6}$ nonzero matrix elements in the sparse system of equations). The basis-functions are quadratic and the typical (tetrahedral) cell size is $5 \mathrm{~cm}$ along the external magnetic field $B_{0}$ and $2 \mathrm{~cm}$ in the directions perpendicular to $B_{0}$. Reaching $1 \%$ relative tolerance on the iterative solver typically requires about 300 iterations per port.

\section{RAPLICASOL/TOPICA benchmark for The ASDEX Upgrade 2-strap antenna}

In ASDEX Upgrade experiment \#29823, a triangularity scan was done. During this triangularity scan, 27 consecutive density profiles were measured, one every $0.2 \mathrm{~s}$. These profiles were measured using a combination of lithium beam spectroscopy and interferometry 25] (for the location of the antennas and diagnostics, see figure 3 in $\sqrt{3}$ ). The 27 profiles are shown in figure 7. From the point of view of the codes, these changing density profiles are the only effect of the triangularity scan: the distance from the antenna to the 
plasma is assumed to remain constant both toroidally and poloidally. At any particular time, a single density profile is available for the whole tokamak: in what follows, we must use the same density profile for antennas 1 and 3 (antennas 1 and 3 are the two-strap antennas, antennas 2 and 4 have a different geometry and are not considered here). The corresponding voltage reflection coefficients at the ports of antennas 1 and 3 were also measured using voltage and current probes. At the time, TOPICA calculations were performed 3, 4] to compute the reflection coefficients. They match the experimental values closely: the RMS difference between the predicted and observed reflection coefficients is 0.05 for antenna 1 and 0.02 for antenna 3. These reflection coefficients $\left|\Gamma_{i}\right|$ are calculated from the S-matrix, which is computed by both TOPICA and RAPLICASOL. The S-matrix relates the incident wave amplitudes to the reflected wave amplitudes: $V_{\text {reflected }}=S V_{\text {incident }}$. The reflection coefficient $\Gamma_{i}=V_{\text {reflected, } i} / V_{\text {incident }, i}$. For dipole phasing on the AUG 2-strap antenna, we may assume that $V_{\text {incident,1 }}=V_{\text {incident, } 2}$, and we get the following expression for $\Gamma_{i}$

$\left[\begin{array}{l}\left|\Gamma_{1}\right| \\ \left|\Gamma_{2}\right|\end{array}\right]=\left|S\left[\begin{array}{l}1 \\ 1\end{array}\right]\right|$

\subsection{Geometries}

The TOPICA calculations with which we wish to compare our RAPLICASOL results were originally done with a curved geometry [3,4. A comparable flat TOPICA geometry exists whose results have been compared with those of the curved geometry [26], and were found to be in close agreement (on the order of $5 \%$ difference in coupled power). We have imported this flat TOPICA geometry into RAPLICASOL (figure 8).

In general, the simplified flat $3 \mathrm{D}$ model in TOPICA can be considered as a rather good approximation of the real curved one, in particular for the estimation of antenna coupling $3,4,26,27$. However, for more local phenomena such as the radiated electric fields, there are significant differences between the flat and the more realistic curved model 27.

To get a more meaningful comparison, we repeated the RAPLICASOL calculations with the flat geometry imported from TOPICA, and repeated the TOPICA calculations with the same flat geometry, thereby eliminating most geometry differences as a source of error (aside from differences in the embedding of the antenna geometry in the tokamak wall, recall figures 3.5).

In the end, we have simulation results for three geometries (figure 9, table 3) and four sets of simulations as described below:

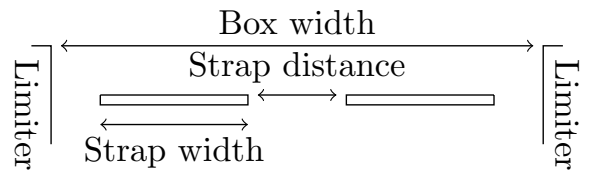

Figure 9. Diagram for comparing the geometries in table 3

\begin{tabular}{l|l|l|l} 
Geometry & $\begin{array}{l}\text { Box } \\
\text { width }\end{array}$ & $\begin{array}{l}\text { Strap } \\
\text { width }\end{array}$ & $\begin{array}{l}\text { Strap } \\
\text { distance }\end{array}$ \\
\hline Real antenna & $0.80 \mathrm{~m}$ & $0.18 \mathrm{~m}$ & $0.21 \mathrm{~m}$ \\
\hline $\begin{array}{l}\text { RAPLICASOL } \\
\text { default }\end{array}$ & $0.74 \mathrm{~m}$ & $0.20 \mathrm{~m}$ & $0.20 \mathrm{~m}$ \\
\hline $\begin{array}{l}\text { TOPICA } \\
\text { curved }\end{array}$ & $0.80 \mathrm{~m}$ & $0.18 \mathrm{~m}$ & $0.21 \mathrm{~m}$ \\
\hline TOPICA flat & $0.65 \mathrm{~m}$ & $0.18 \mathrm{~m}$ & $0.15 \mathrm{~m}$ \\
\hline $\begin{array}{l}\text { RAPLICASOL } \\
\text { imported flat }\end{array}$ & $0.65 \mathrm{~m}$ & $0.18 \mathrm{~m}$ & $0.15 \mathrm{~m}$
\end{tabular}

Table 3. Relevant measurements of the antenna geometries. Distances are measured in a straight line, not along the curvature. All geometries are intended to represent the ASDEX Upgrade 2-strap antenna. Some of these measurements (shaded in red) differ from the correct value. This, to our knowledge, is simply due to oversights during the construction of these geometries, and was not realized at the time they were constructed.

- "TOPICA curved": TOPICA calculations with the curved 2-strap geometry (from [3, 4]).

- "TOPICA flat": TOPICA calculations with the flat 2-strap geometry.

- "RAPLICASOL default": RAPLICASOL calculations with its default (flat) geometry.

- "RAPLICASOL imported flat": RAPLICASOL calculations with the "TOPICA flat" geometry.

\subsection{Reflection coefficients and coupling resistance}

Figures 10 and 11 contain the experimentally measured absolute reflection coefficients for antennas 1 and 3, as well as the numerical results for the four cases listed above.

Because the density profile in front of both antennas is assumed to be the same, and the geometry for antenna 1 and 3 are the same, the numerical results in figures 10 (antenna 1) and 11 (antenna 3) are identical, only the experimental measurements differ. There are several possible reasons for the difference in the experimental measurements. At the time this experiment was done (March 2013), antenna 3 had a closed Faraday screen, which is consistent with higher reflection coefficients 28] (all antenna models in this paper have open Faraday screens). Recent measurements indicate that antenna 1 is a few $\mathrm{mm}$ closer to the plasma than antenna 3 , which is also 


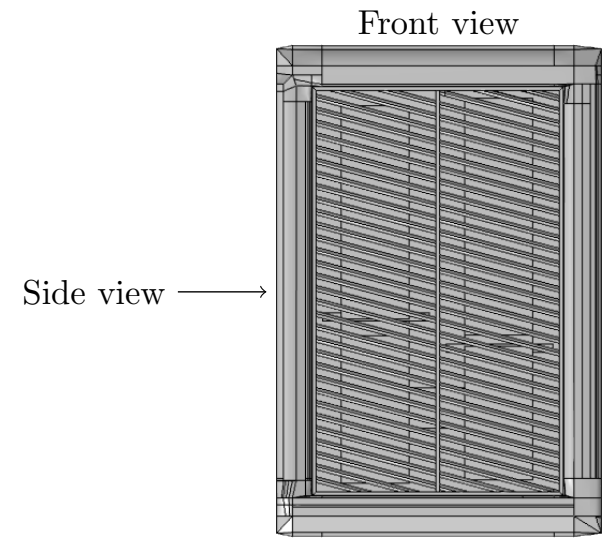

Figure 8. TOPICA flat antenna geometry, front and side view.

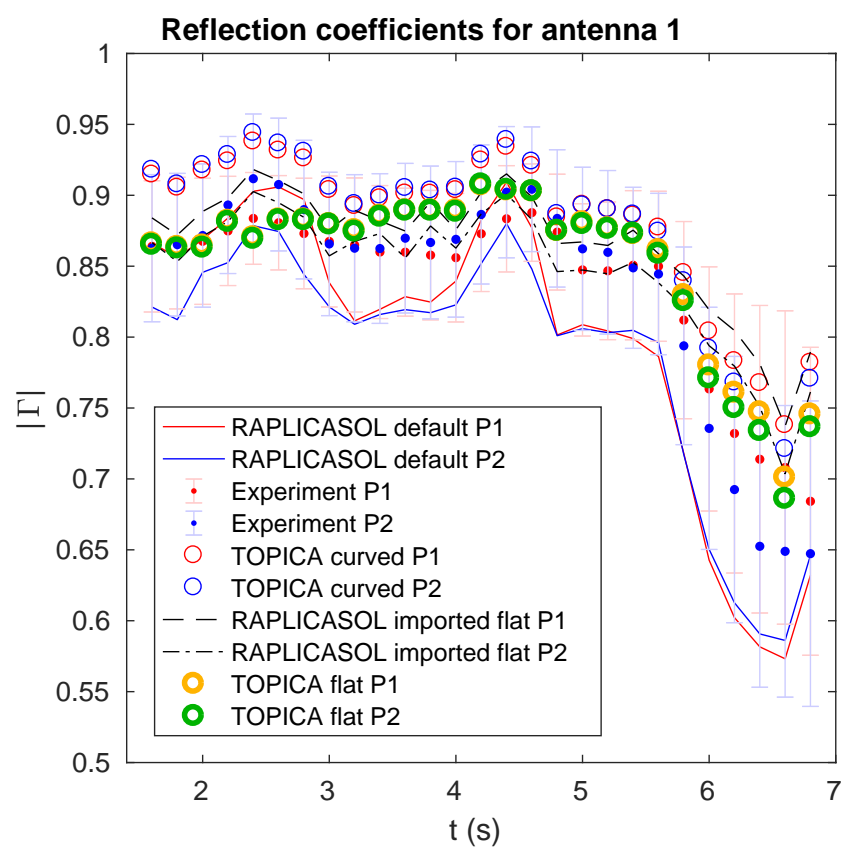

Figure 10. Reflection coefficients for both ports (P1 and P2): comparison with antenna 1

consistent with lower reflection (better coupling) at antenna 1 , but 3 concludes that the difference in radial position is too small to explain the observed differences. Toroidal non-uniformity of the plasma and/or RF probe calibration uncertainties 3 may also play a role.

We see that "TOPICA curved", "TOPICA flat", and "RAPLICASOL imported" give very similar results for the reflection coefficient (table 4). "TOPICA flat" and "RAPLICASOL imported" are geometrically nearly identical, with the only difference being the embedding in the tokamak wall (see section 3). The small remaining difference is either due to this embedding, to the different plasma model (hot plasma in FELICE vs. cold plasma in RAPLICASOL) or to
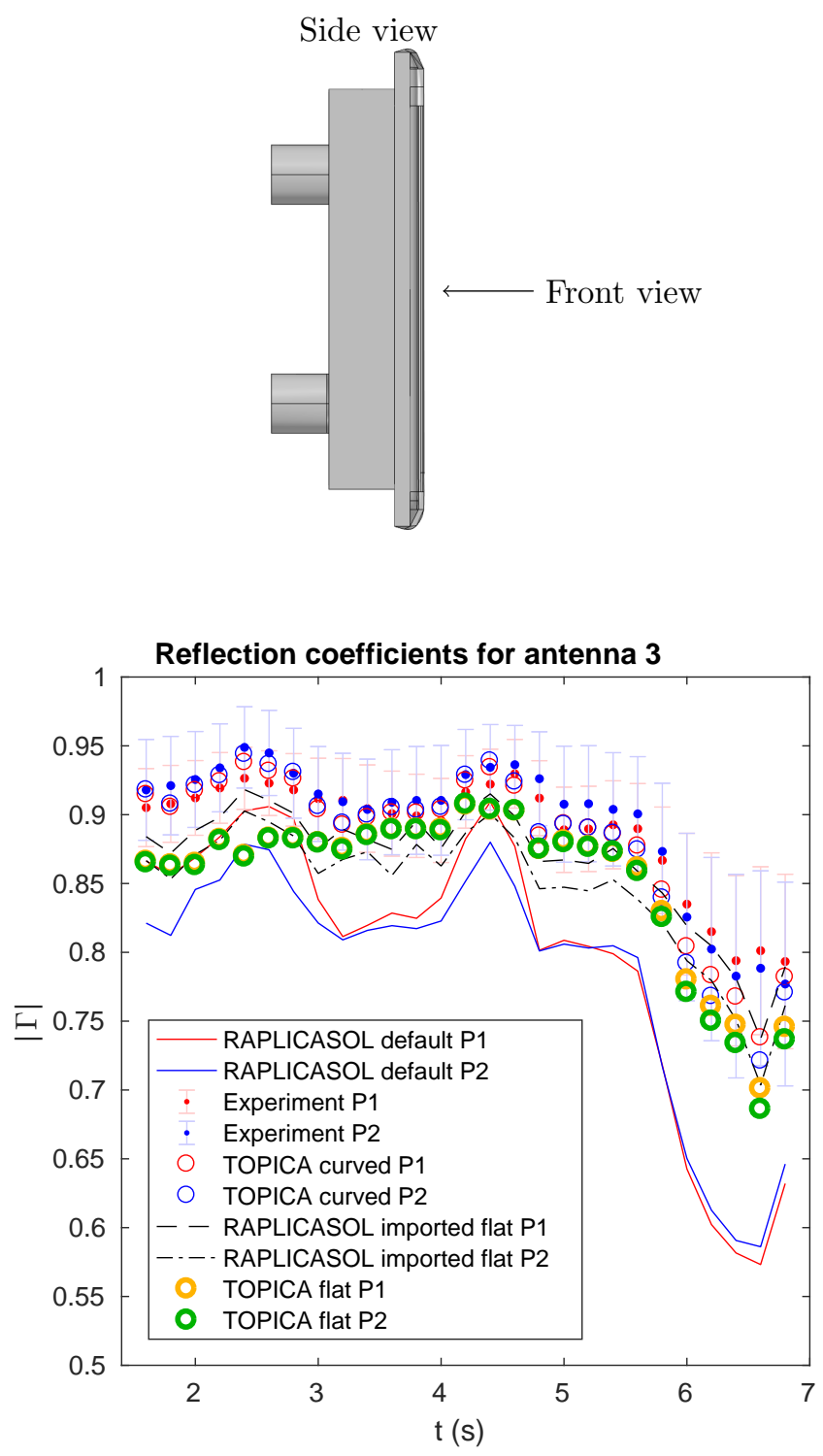

Figure 11. Reflection coefficients for both ports (P1 and P2): comparison with antenna 3

the different way the density profile is modified to deal with the LH resonance (see section 3.1). (There is one odd point in "TOPICA flat": the fifth point, at $2.4 \mathrm{~s}$, which seems to be a local minimum where the same point is a local maximum for all cases other than "TOPICA flat". We suspect this is due to a suboptimal setting of one of the TOPICA parameters, but we were not able to test this due to CPU time constraints).

That the "TOPICA curved" and "TOPICA flat" results are similar is entirely in line with the results of [26]. The "RAPLICASOL default" geometry gives results that are only qualitatively similar to the other three, which we suspect is due to the geometry differences, see table 3 . 


\begin{tabular}{|c|c|c|c|c|c|c|c|c|c|c|}
\hline & \multicolumn{2}{|c|}{$\begin{array}{l}\text { RAPLICASOL } \\
\text { default }\end{array}$} & \multicolumn{2}{|c|}{$\begin{array}{l}\text { Experiment } \\
\text { (antenna 3) }\end{array}$} & \multicolumn{2}{|c|}{$\begin{array}{l}\text { TOPICA } \\
\text { curved }\end{array}$} & \multicolumn{2}{|c|}{ TOPICA flat } & \multicolumn{2}{|c|}{$\begin{array}{l}\text { RAPLICASOL } \\
\text { imported flat }\end{array}$} \\
\hline $\begin{array}{l}\text { RAPLICASOL } \\
\text { default }\end{array}$ & 0 & 0 & 0.1032 & 0.1126 & 0.0895 & 0.0942 & 0.0779 & 0.0744 & 0.0910 & 0.0738 \\
\hline $\begin{array}{l}\text { Experiment } \\
\text { (antenna 3) }\end{array}$ & 0.1032 & 0.1126 & 0 & 0 & 0.0187 & 0.0221 & 0.0391 & 0.0476 & 0.0269 & 0.0537 \\
\hline TOPICA curved & 0.0895 & 0.0942 & 0.0187 & 0.0221 & 0 & 0 & 0.0298 & 0.0323 & 0.0228 & 0.0405 \\
\hline TOPICA flat & 0.0779 & 0.0744 & 0.0391 & 0.0476 & 0.0298 & 0.0323 & 0 & 0 & 0.0227 & 0.0204 \\
\hline $\begin{array}{l}\text { RAPLICASOL } \\
\text { imported flat }\end{array}$ & 0.0910 & 0.0738 & 0.0269 & 0.0537 & 0.0228 & 0.0405 & 0.0227 & 0.0204 & 0 & 0 \\
\hline
\end{tabular}

Table 4. Root-mean-square differences of the reflection coefficients (one for each port).

The reflection coefficients $\left|\Gamma_{i}\right|$ relate to the perport loading resistance $R_{L, i}$ via the Standing Wave Ratio

$\operatorname{SWR}=\frac{1+\left|\Gamma_{i}\right|}{1-\left|\Gamma_{i}\right|}$

$R_{L, i}=\frac{Z_{0}}{\mathrm{SWR}}$

where the characteristic impedance of the coaxial feeders is $Z_{0}=25 \Omega$.

A comparison between the predicted and observed $R_{L, i}$ is shown in figures 12 and 13 . Assuming the same incident voltage $V_{i n}$ on both ports, the total power is

$P=\frac{V_{i n}^{2}}{2 Z_{0}} \sum_{i}\left(1-\left|\Gamma_{i}\right|^{2}\right)$

For a desired coupled power $P$, the incident port voltage should be

$V_{\text {in }}=\sqrt{\frac{2 P Z_{0}}{\sum_{i}\left(1-\left|\Gamma_{i}\right|^{2}\right)}}$

The corresponding maximum voltage in the transmission lines is

$V_{\text {max }, j}=\left(1+\left|\Gamma_{j}\right|\right) \sqrt{\frac{2 P Z_{0}}{\sum_{i}\left(1-\left|\Gamma_{i}\right|^{2}\right)}}$

The maximum port voltages for a coupled power of $1 \mathrm{MW}$ are shown in figures 14 and 15 .

\subsection{Complex S-matrix entries}

In the previous subsection we considered experimentally accessible quantities such as $|\Gamma|, R_{L}$ and $V_{\max }$, as predicted by RAPLICASOL and TOPICA. All these quantities are derived from the 4 complex entries of the S-matrix, which we cannot measure directly on AUG (although there are plans to do so based on [29]). They are computed by both RAPLICASOL and TOPICA, so we can compare them, albeit without experimental references. The absolute values and arguments of the 4 S-matrix entries are shown in figures 16 and 17 , and generally show fairly good agreement.

\section{RAPLICASOL/TOPICA benchmark for a 4-strap test-case antenna}

In this section, we compare RAPLICASOL and TOPICA calculations for a 4-strap antenna, similar to the ICRF antennas of the WEST tokamak 30].

\subsection{Geometry}

The test-case antenna, illustrated in figure 18 is a simple flat 4-strap antenna with no Faraday Screen. The operation frequency is set to $55 \mathrm{MHz}$, similarly to the WEST ICRF launchers. The four straps are separated by poloidal and toroidal septa. The straps are connected to the antenna box at one extremity and they are fed by coaxial transmission lines at the other extremity (the characteristic impedance of these transmission lines is $Z_{0}=44 \Omega$ ). All conductors are supposed to be Perfect Electric Conductors. The front faces of the straps are located $35 \mathrm{~mm}$ behind the antenna aperture (plane A of figure 18). A vacuum layer of width $D_{\text {vac }}$ separates the antenna aperture from the magnetized plasma. The latter is a cold radially inhomogeneous deuterium-hydrogen plasma where the hydrogen concentration is taken as $5 \%$. The density and magnetic profiles are shown in figure 19 . The parameter $D_{\text {vac }}$ is scanned from 2 to $42 \mathrm{~mm}$ with a $10 \mathrm{~mm}$ step as if the antenna was radially moved closer to or away from the plasma. In RAPLICASOL simulations the plasma radial width is $10 \mathrm{~cm}$ and, as before, the simulation region terminates with PMLs (section 2.3). Meshing the domain with tetrahedra whose size is at most a few millimetres leads to about 6 million degrees of freedom. In such conditions, a $4 \times 4$ Z-matrix calculation requires about 20 hours and $80 \mathrm{~Gb}$ of memory.

\subsection{Comparison of strap impedances and $4 \times 4$ impedance matrices}

At first, we compare the impedances seen at the strap inputs $\left(Z_{i}=R_{i}+j X_{i}, i \in\{1,2,3,4\}\right)$ when the 


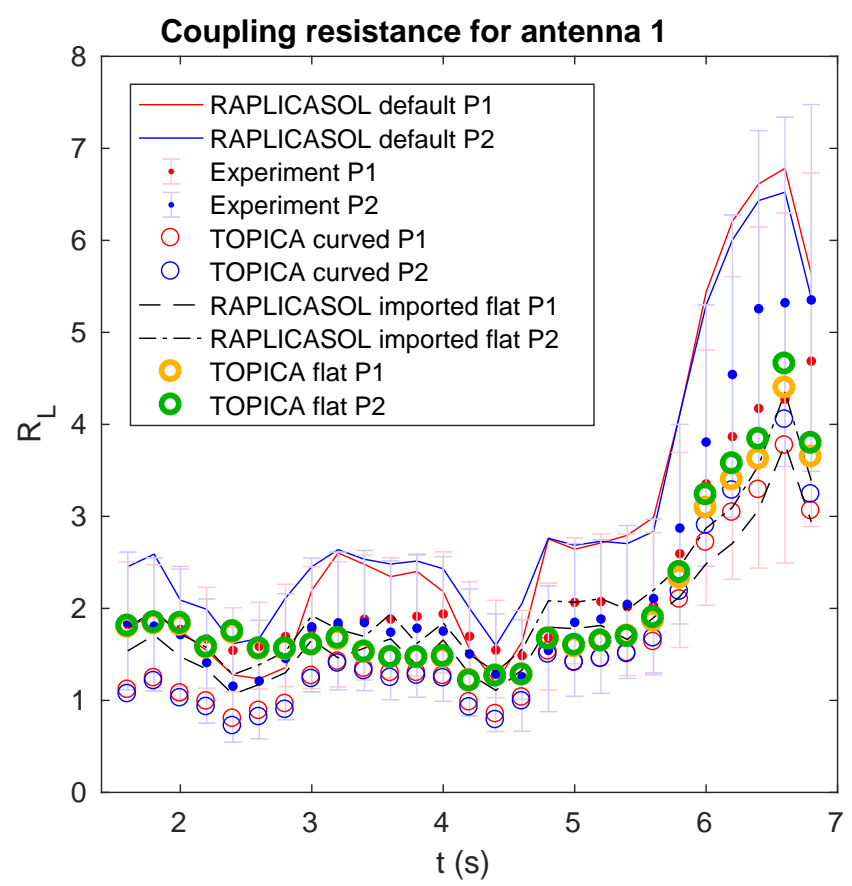

Figure 12. Loading resistances for both ports ( $\mathrm{P} 1$ and $\mathrm{P} 2)$ : comparison with antenna 1

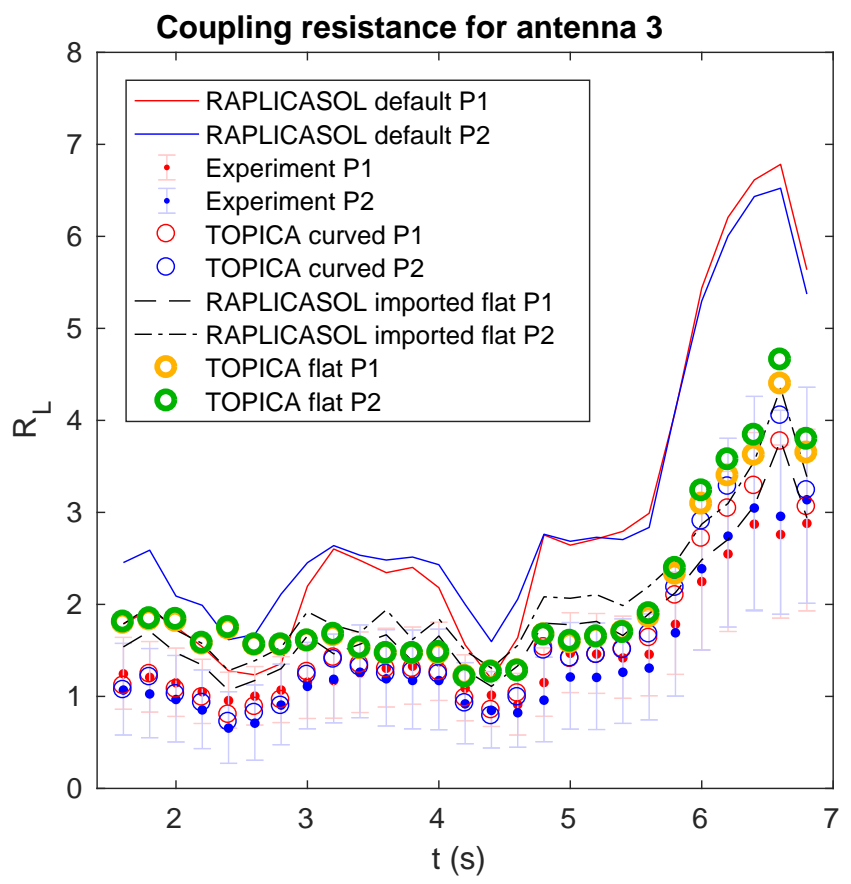

Figure 13. Loading resistances for both ports (P1 and P2): comparison with antenna 3

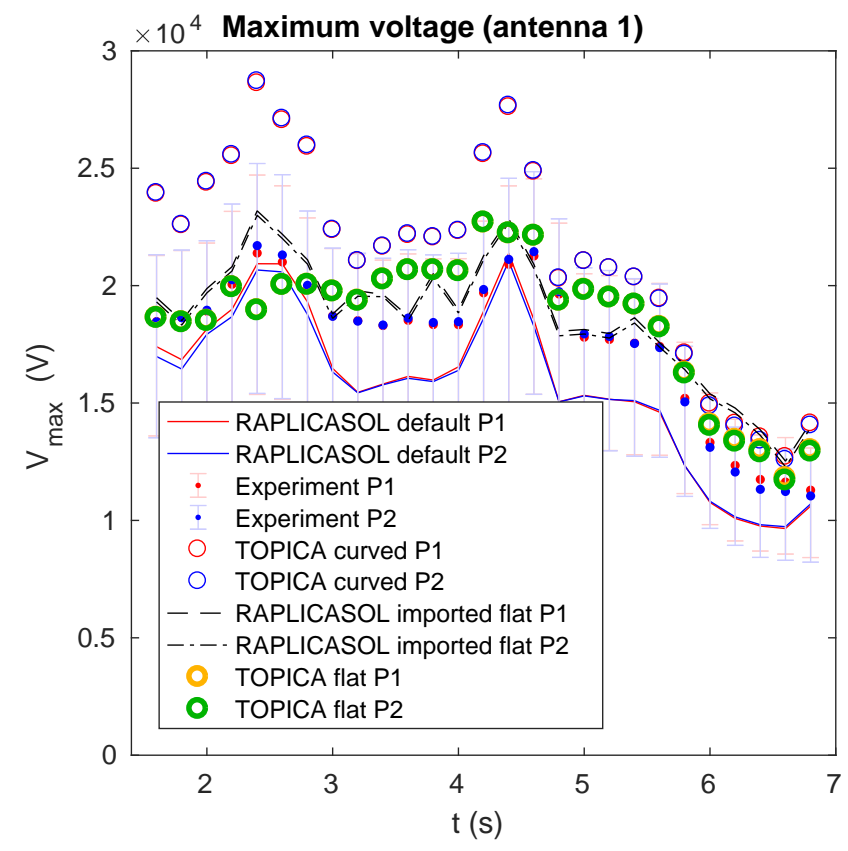

Figure 14. Maximum voltage in the transmission lines required for $1 \mathrm{MW}$ of coupled power: comparison with antenna 1 .

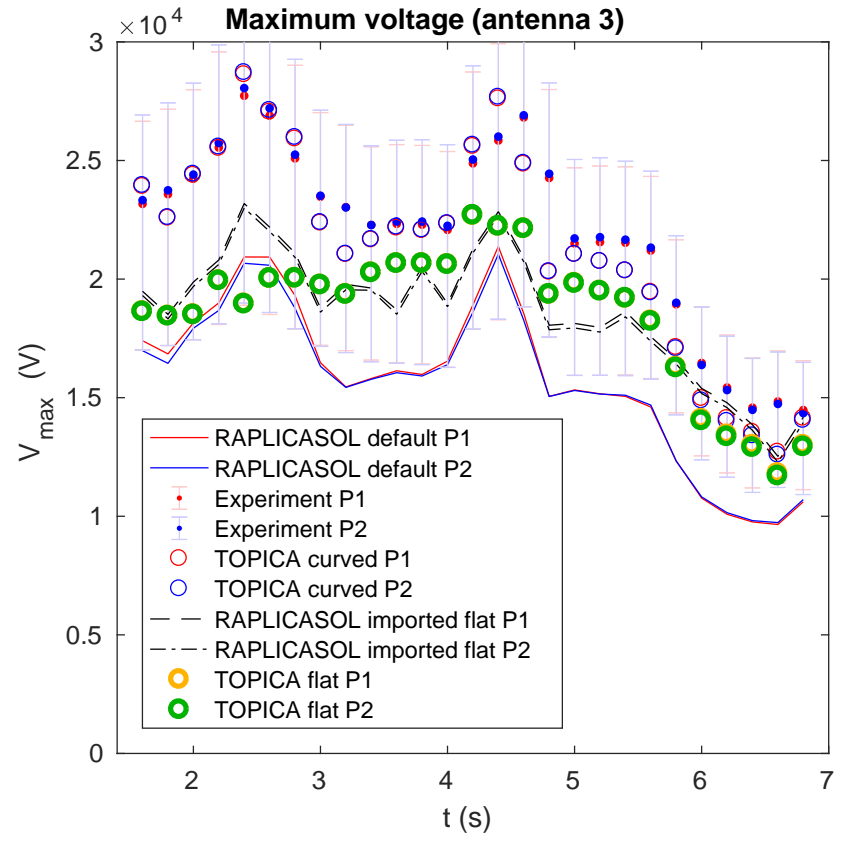

Figure 15. Maximum voltage in the transmission lines required for $1 \mathrm{MW}$ of coupled power: comparison with antenna 3. 

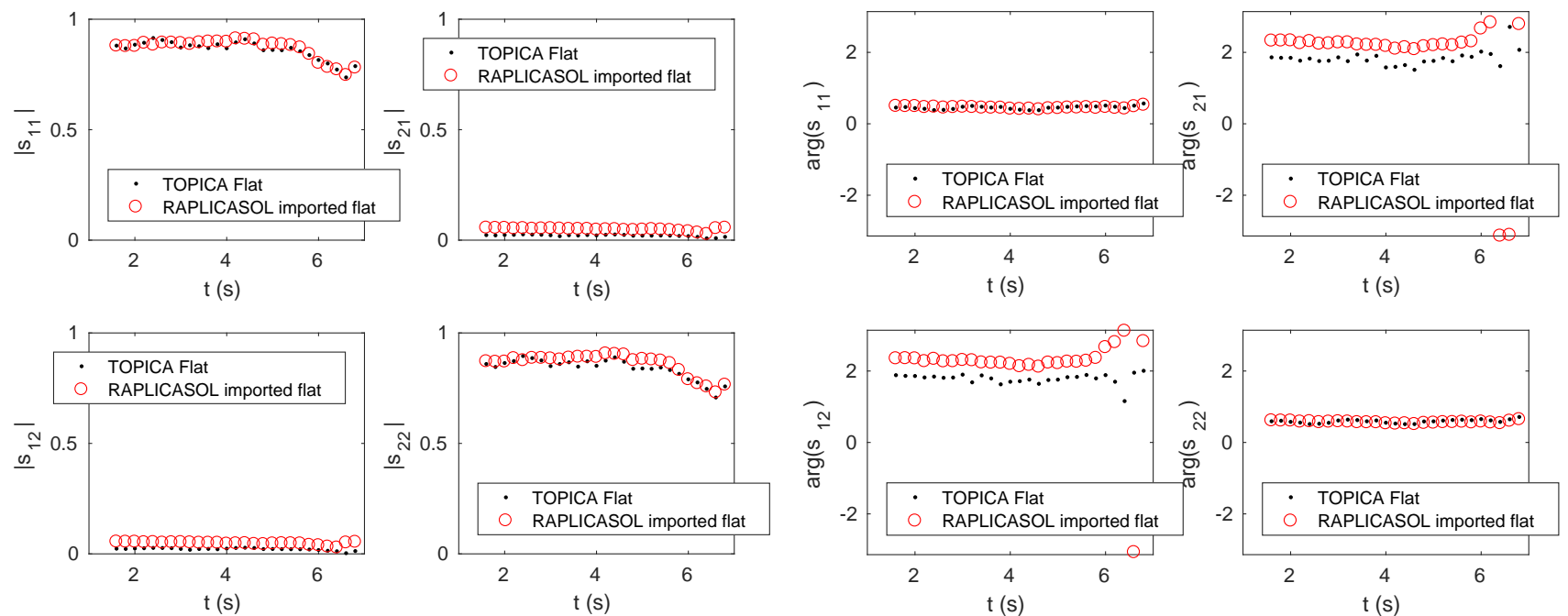

Figure 16. Absolute value of the 4 complex S-matrix entries for the 27 density profiles
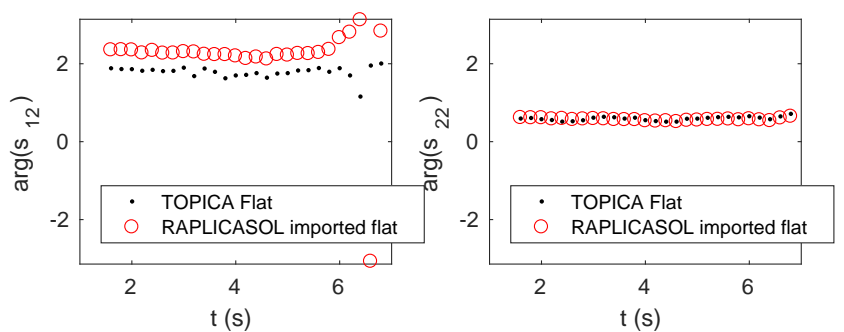

Figure 17. Argument of the 4 complex S-matrix entries for the 27 density profiles
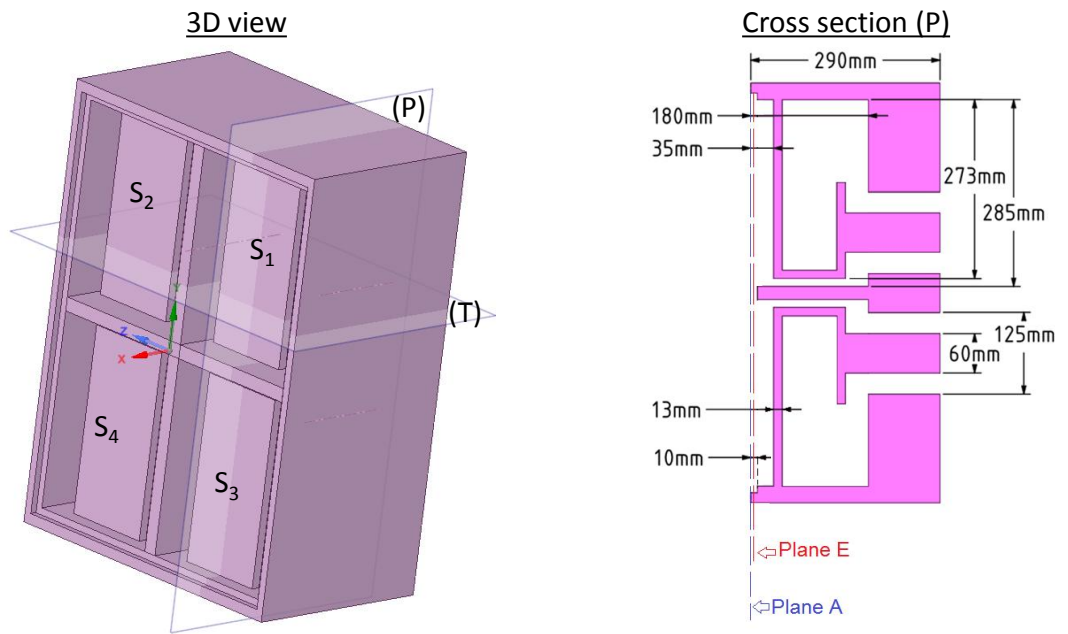

Cross section (T)

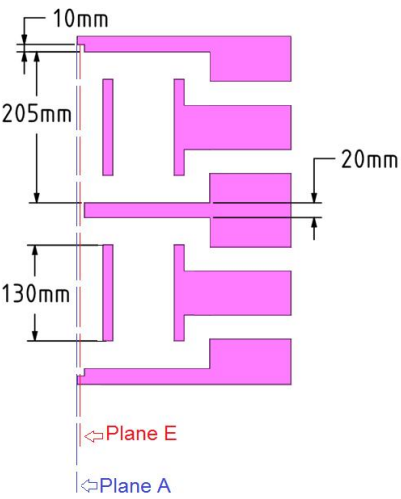

Figure 18. The 4-strap test-case antenna. (a) 3D view. The straps numbering and two cross sections are visible. (b) Poloidal cross section. (c) Toroidal cross section. The antenna aperture corresponds to the plane A which is shown in (b) and (c).
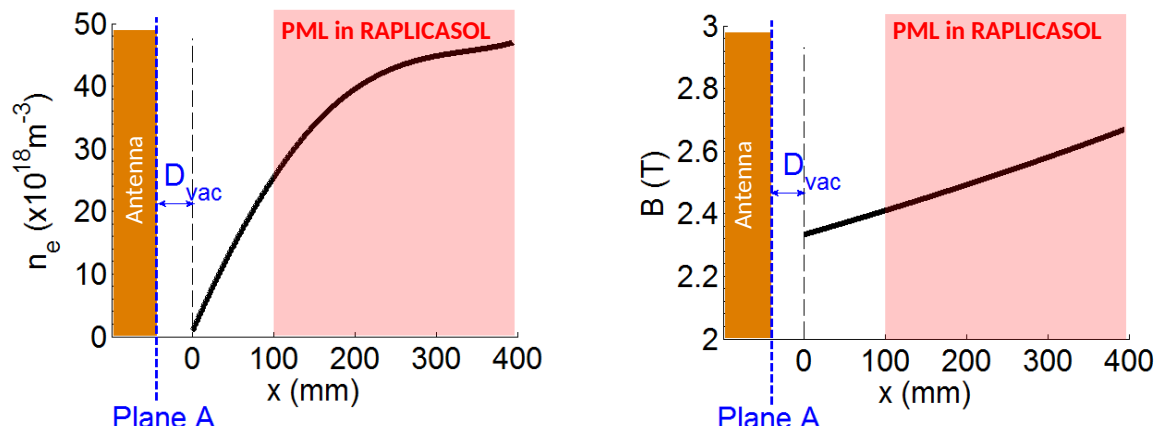

Figure 19. Density and magnetic field profiles in front of the test-case antenna. 

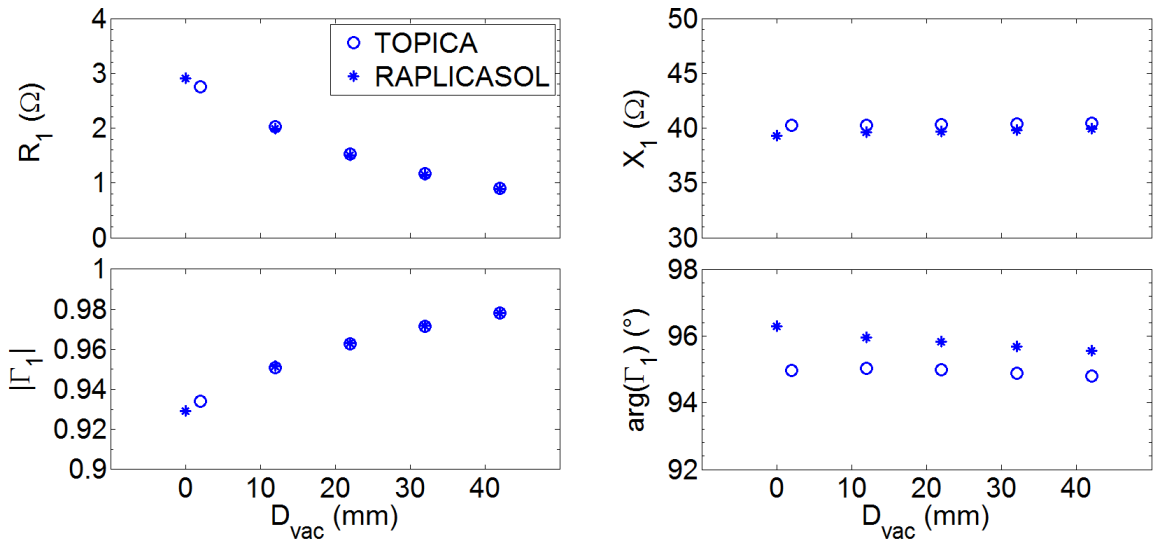

Figure 20. $R_{i}, X_{i},\left|\Gamma_{i}\right|$ and $\arg \left(\Gamma_{i}\right)$ as function of $D_{\text {vac }}$ for $i=1$ and $I=I_{D}=[+1 A,-1 A,-1 A,+1 A]^{T}$. Similar results are obtained for the other straps.

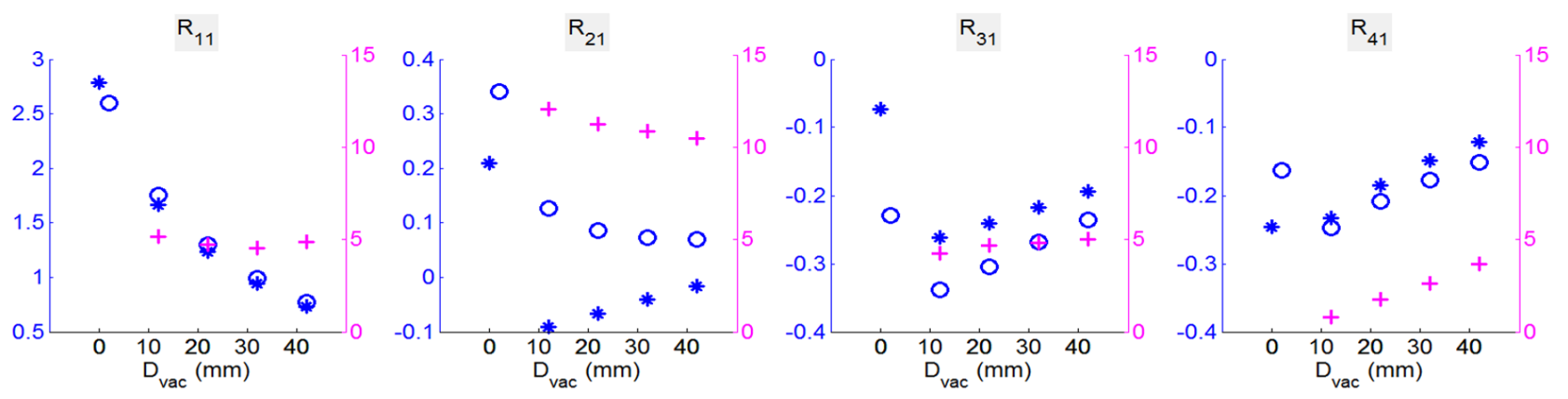

Figure 21. $R_{i j}$ as function of $D_{\mathrm{vac}}$ (left y-axis) for $i \in\{1,2,3,4\}$ and $j=1$ as calculated by TOPICA and RAPLICASOL. The percentual discrepancy between the codes $\left|\frac{R_{i j, \mathrm{RAPLICASOL}}-R_{i j, \mathrm{TOPICA}}}{\sqrt{\sum_{i} R_{i j, \mathrm{TOPICA}}^{2}}}\right|$ is given by the right y-axis.

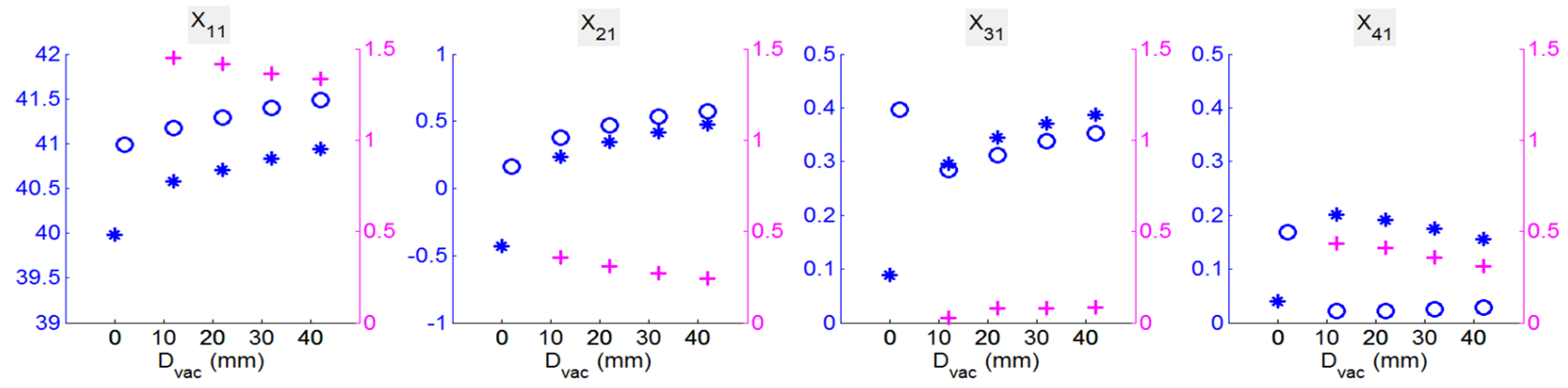

Figure 22. $X_{i j}$ as function of $D_{\mathrm{vac}}$ (left y-axis) for $i \in\{1,2,3,4\}$ and $j=1$ as calculated by TOPICA and RAPLICASOL. The percentual discrepancy between the codes $\left|\frac{X_{i j, \mathrm{RAPLICASOL}}-X_{i j, \mathrm{TOPICA}}}{\sqrt{\sum_{i} X_{i j, \mathrm{TOPICA}}^{2}}}\right|$ is given by the right y-axis. 
antenna is excited by a current vector $I$

$I=I_{D}=\left[\begin{array}{c}I_{1} \\ I_{2} \\ I_{3} \\ I_{4}\end{array}\right]=\left[\begin{array}{c}1 A \\ -1 A \\ -1 A \\ 1 A\end{array}\right]$

corresponding to an ideal dipole excitation. The impedances $Z_{i}$ are taken as $Z_{i}=V_{i} / I_{i}$ where the voltage vector $V=\left[V_{1}, V_{2}, V_{3}, V_{4}\right]^{T}$ is equal to $Z I$ where $Z=R+j X$ is the $4 \times 4 \mathrm{Z}$-matrix computed by each code. The results for the real $\left(R_{i}\right)$ and imaginary $\left(X_{i}\right)$ parts of $Z_{i}$ are shown in figure 20 for $i=1$, together with the modulus and the argument of the reflection coefficient $\Gamma_{i}=\frac{Z_{i}-Z_{0}}{Z_{i}+Z_{0}}$. Very similar results are obtained for $i \in\{2,3,4\}$. Figure 20 shows a good agreement between RAPLICASOL and TOPICA. The discrepancy between the codes is around or below $\pm 5 \%, \pm 2 \%, \pm 2 \%, \pm 1^{\circ}$ for $R_{i}, X_{i},\left|\Gamma_{i}\right|$ and $\arg \left(\Gamma_{i}\right)$ respectively. As one would expect, $R_{i}$ decreases with $D_{\text {vac }}$ since as $D_{\text {vac }}$ increases the waves radiated by the antenna have to tunnel through a larger evanescent region. It should be noted that while TOPICA's formulation allows handling $D_{\text {vac }}$ as small as $2 \mathrm{~mm}$, doing the same in RAPLICASOL is too costly in terms of meshing. Hence, for the case of the smallest Dvac, the vacuum layer has been eliminated in RAPLICASOL $\left(D_{\text {vac }}=0 \mathrm{~mm}\right.$ in lieu of $\left.D_{\text {vac }}=2 \mathrm{~mm}\right)$. Thus, strictly speaking, comparisons between RAPLICASOL and TOPICA for the smallest considered $D_{\text {vac }}$ is not valid, but the results are shown for completeness.

As a more general comparison between the codes, we then compare the elements $R_{i j}$ and $X_{i j}$ of respectively the real $(R)$ and imaginary $(X)$ parts of the Z-matrix (figures 21 and 22). If we define the relative error naively as $\left|1-\frac{A_{i j, \mathrm{RAPLICASOL}}}{A_{i j, \mathrm{TOPICA}}}\right|$, where $A$ is $R$ or $X$, we find it is around or below $5 \%$ for the diagonal elements, but sometimes large for off-diagonal elements (e.g. $180 \%$ and $800 \%$ for respectively $R_{[21}$ and $X_{41}$ at $\left.D_{\text {vac }}=20 \mathrm{~mm}\right)$.

Because the amplitude of the mutual coupling terms is small with respect to the amplitude of the diagonal terms, it is more appropriate to define the discrepancy between the codes as $\left|\frac{A_{i j, \mathrm{RAPLICASOL}}-A_{i j, \mathrm{TOPICA}}}{\sqrt{\sum_{i} A_{i j, \mathrm{TOPICA}}^{2}}}\right|$ where $A$ is $R$ or $X$ (this is the error metric used in figures 21 and 22). We conclude that RAPLICASOL and TOPICA produce globally similar values for the $Z$ matrices. The discrepancies between the codes will be further evaluated in the next section.

\subsection{Discrepancy between RAPLICASOL and} TOPICA through RF network calculations

It was shown in section 5.2 that RAPLICASOL and TOPICA calculate very similar values for the impedances at the strap inputs $Z_{i}(i \in$ $\{1,2,3,4\})$ for a straps current vector $I=I_{D}=$ $[+1 A,-1 A,-1 A,+1 A]^{T}$ (see figure 20). However, was also mentioned that while the relative error between the codes on the diagonal elements of the $Z$-matrix is small, there is a considerable relative error for certain mutual coupling terms (figures 21 and 22 . Since the impedance of a strap of index $i$ is $Z_{i}=\sum_{j=1}^{4} Z_{i j} I_{j} / I_{i}$, one understands that the discrepancy between the codes' $Z_{i}$ values depends not only on the discrepancy between the $Z_{i j}$ parameters (small for $i=j$, and large for some $i \neq j$ ) but also on the current vector $I$. Hence, one cannot a priori exclude the existence of current vectors that can lead to large discrepancies between the $Z_{i}$ calculated by both codes.

Instead of comparing the strap impedances when a current vector is non-self-consistently imposed at the strap inputs (as performed in section 5.2), we perform in this section a benchmark between RAPLICASOL and TOPICA through advanced and realistic RF network calculations. The latter are similar to the calculations that are performed for the WEST ICRF launchers 31] and for the JET's ILA 32 to simulate their operation on plasma and to simulate the realtime control of their impedance matching systems. Here the array of straps of figure 18 is excited by the same feeding circuit as the one the WEST ICRF launchers (see figure 23) (for the details about the WEST ICRF launchers and their load-resilient feeding circuit, see $30,31,33$ ). Every component of figure 23 is characterized by: an S-matrix derived from HFSS 34 for the feeding circuit (the variable capacitors, the bridges, the impedance transformers, the RF windows and the service stubs) and by a Z-matrix derived from RAPLICASOL or TOPICA for the array of straps. As for WEST ICRF launchers, the launcher of figure 22 is powered by two incident waves carrying powers of $P_{i n c, 1}$ and $P_{i n c, 2}=P_{i n c, 1}$ and phase-shifted by $\Delta \varphi$.

At this point it should be mentioned that a task of great importance for a numerical ICRF antenna code is to correctly predict the maximum power that can be coupled by the antenna to a given plasma, and to correctly predict the settings of the impedance matching network. In particular these predictive capabilities are crucial in the antenna design phase, where one has to optimize the geometry of the antenna in order to enhance its power capabilities and to insure that the settings for the impedance matching elements fall well within the ranges given in their datasheets.

For each $D_{\text {vac }}$ case, and using a RAPLICASOL or a TOPICA Z-matrix, we assess in this section: (a) 
the settings of the variable capacitors that impedancematch the launcher (the settings of the variable capacitors is found iteratively using an algorithm similar to the one of $[31,32]$ ), and, (b) the maximum power that can be coupled by the launcher at matching $\left(P_{i n c, 1}=P_{i n c, 2}\right.$ is increased until reaching $V_{\max }$ or $I_{\max }$ at a strap input with $V_{\max }$ and $I_{\max }$ taken respectively as $35 \mathrm{kV}$ and $1 \mathrm{kA}$ ).

The circuit of figure 23 involves multiport components described by $\mathrm{S}$ or Z-matrices and cannot be solved using Kirchhoff's laws. SIDON 31 is instead used here to solve the RF circuit: knowing the $\mathrm{S}$ or $\mathrm{Z}$ matrices for every component, the connections between them, and the excitations at the launcher's inputs (i.e. the values of $P_{i n c, 1}, P_{i n c, 2}$ and $\left.\Delta \varphi\right)$, SIDON finds the voltages and currents at all the components ports, in particular at the strap inputs.

Figure 23 shows the maximum power that can be coupled by the launcher of figure 23 and the settings of the variable capacitors at matching as computed by SIDON using the Z-matrices obtained from RAPLICASOL or TOPICA. The 4 cases of $D_{\text {vac }}(12,22,32$ and $42 \mathrm{~mm})$ and 8 cases of $\Delta \varphi$ $\left(-135^{\circ},-90^{\circ},-45^{\circ}, 0^{\circ},+45^{\circ},+90^{\circ},+135^{\circ}\right.$ and $\left.180^{\circ}\right)$ are considered in figure 24, and the error is taken as $\left|1-\frac{P_{\text {coupled,RAPLICASOL }}}{P_{\text {coupled,TOPICA }}}\right|$ for the power, and $C_{i, \text { RAPLICASOL }}-C_{i, \text { TOPICA }}$ for the capacitors' values $(i \in\{1,2,3,4\})$. The discrepancy on the coupled power between the RAPLICASOL and TOPICA is generally below $10 \%$, and the discrepancy for the matching capacitors is generally minor and below $1.5 \mathrm{pF}$ (for comparison, the WEST ICRF capacitors cover a 15 to $150 \mathrm{pF}$ range [30], compared to which a difference of $1.5 \mathrm{pF}$ is minor).

\subsection{Comparison of the electric fields near the antenna aperture}

This paper focuses on comparing quantities of direct experimental interest, like the S-matrix, coupling resistance, and matching settings. It is also possible to compare quantities that are not so easily experimentally accessible, such as the electric field in the antenna 35 and currents induced on the antenna surface. Figures 25/26 and 27 show such a comparison, for $1 \mathrm{MW}$ of coupled power. We show the electric field components on plane E in figure $18(5 \mathrm{~mm}$ behind plane $\mathrm{A}$, the plane of the leading edge of the limiters). We see that the electric fields as calculated by RAPLICASOL are in good agreement with those calculated by TOPICA.

\section{Conclusion}

In this paper we show that the Finite Element code RAPLICASOL, using a simple cold plasma description of the plasma near the antenna, can predict comparable port reflection coefficients, port impedances, coupling resistances, and optimal matching settings, as the TOPICA code. The difference in predicted reflection coefficients is about $2 \%$ for the AUG 2-strap antenna. The difference in the predicted maximal coupled power on a 4-strap WEST-like antenna is generally below $10 \%$. This good agreement is achieved at a fraction of the computational cost in terms of RAM and CPU requirements.

\section{Acknowledgements}

The authors thank I. Stepanov for providing us with the experimental data and the corresponding TOPICA calculations ("TOPICA curved"), and also R. Bilato for relevant discussions.

The "TOPICA flat" calculations were performed on the Marconi supercomputer 17].

This work has been carried out within the framework of the EUROfusion Consortium and has received funding from the Euratom research and training programme 2014-2018 under grant agreement No 633053. The views and opinions expressed herein do not necessarily reflect those of the European Commission.

\section{References}

[1] D. Milanesio, O. Meneghini, V. Lancellotti, R. Maggiora, and G. Vecchi. A multi-cavity approach for enhanced efficiency in TOPICA RF antenna code. Nuclear Fusion, 49(11):115019, 2009.

[2] V. Lancellotti, D. Milanesio, R. Maggiora, G. Vecchi, and V. Kyrytsya. TOPICA: an accurate and efficient numerical tool for analysis and design of ICRF antennas. Nuclear Fusion, 46(7):S476, 2006.

[3] I. Stepanov, J.M. Noterdaeme, V. Bobkov, H. Faugel, D. Coster, D. Milanesio, R. Maggiora, G. Siegl, R. Bilato, M. Brambilla, G. Verdoolaege, F. Braun, H. Fünfgelder, R. D'Inca, W. Suttrop, A. Kallenbach, J. Schweinzer, E. Wolfrum, R. Fischer, A. Mlynek, V. Nikolaeva, L. Guimarais, and the ASDEX Upgrade team. A detailed comparison of antenna impedance measurements on ASDEX Upgrade with the ion cyclotron range of frequencies antenna code TOPICA. Nuclear Fusion, 55(11):113003, 2015.

[4] I. Stepanov. Ion Cyclotron Range of Frequencies (ICRF) power coupling and plasma density profile. $\mathrm{PhD}$ thesis, Ghent University, 2015.

[5] https://www.comsol.com/.

[6] Ruben Otin. ERMES: A nodal-based finite element code for electromagnetic simulations in frequency domain. Computer Physics Communications, 184(11):2588-2595, 2013.

[7] J. Jacquot, V. Bobkov, L. Colas, S. Heuraux, A. Křivská, L. $\mathrm{Lu}$, and J.M. Noterdaeme. Full wave propagation modelling in view to integrated ICRH wave cou- 

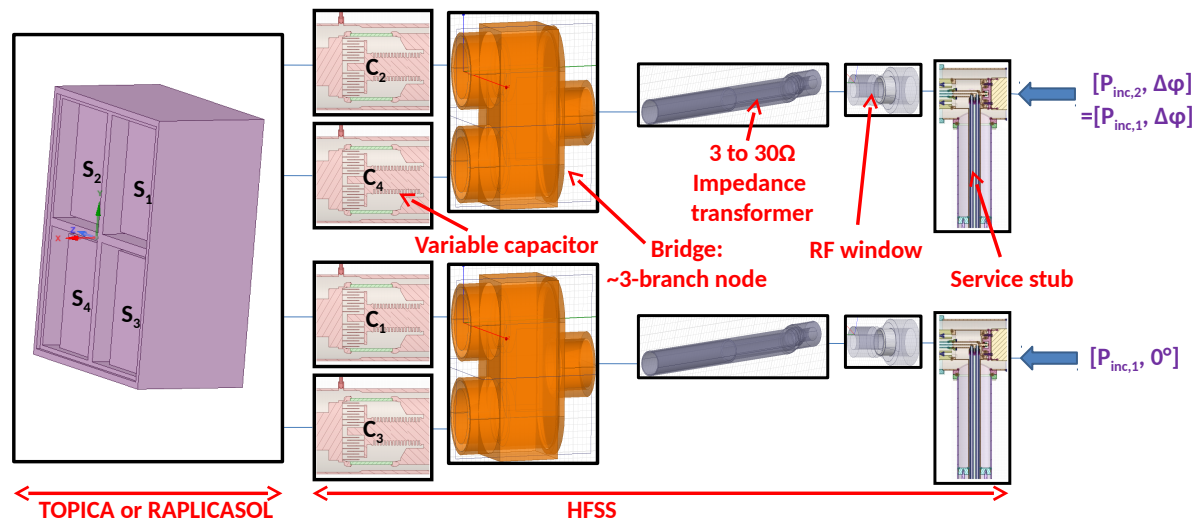

Figure 23. The RF network that is solved in section 5.3. The array of straps of figure 17 is excited by the feeding circuit of the WEST ICRF launchers. A capacitor $C_{i}$ is connected in series to the strap of same index (i.e. $S_{i}$ ).
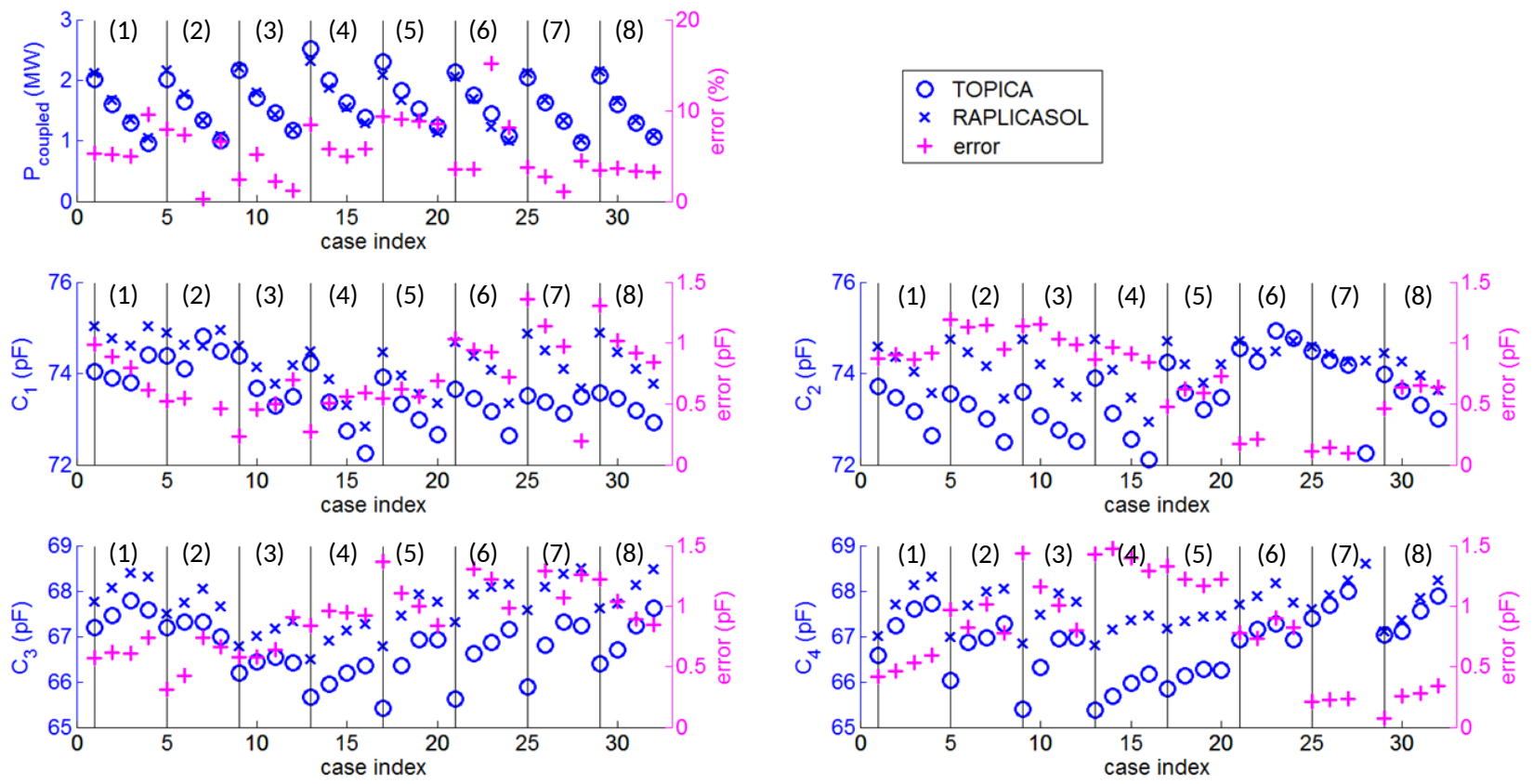

Figure 24. Left y-axes: the maximum power that can be coupled by the launcher of figure 22 and the settings of the variable capacitors at matching as computed by SIDON for the straps Z-matrices obtained from RAPLICASOL or TOPICA. Right y-axes: the discrepancy between the codes. The regions numbered from (1) to (8) correspond to $\Delta \varphi$ increasing from $-135^{\circ}$ to $180^{\circ}$ with a $45^{\circ}$ step. In each region, $D_{\text {vac }}$ increases from 12 to $42 \mathrm{~mm}$ with a $10 \mathrm{~mm}$ step when incrementing the case index.

pling/RF sheaths modelling. AIP Conference Proceedings, 1689(1):050008, 2015.

[8] W. Zhang, V. Bobkov, J.M. Noterdaeme, W. Tierens, R. Bilato, D. Carralero, D. Coster, J. Jacquot, P. Jacquet, T. Lunt, R. A. Pitts, V. Rohde, G. Siegl, H. Fünfgelder, D. Aguiam, A. Silva, L. Colas, S. Ceccuzzi, and the ASDEX Upgrade Team. Effects of outer top gas injection on ICRF coupling in ASDEX Upgrade: towards modelling of ITER gas injection. Plasma Physics and Controlled Fusion, 59(7):075004, 2017.

[9] L. Colas, J. Jacquot, J. Hillairet, W. Helou, W. Tierens, S. Heuraux, E. Faudot, L. Lu, and G. Urbanczyk. Perfectly matched layers for time-harmonic electromagnetic wave propagation in curved gyrotropic media. Submitted to Journal of Computational Physics, 2018.
[10] S Shiraiwa, O Meneghini, R Parker, P Bonoli, M Garrett, MC Kaufman, JC Wright, and S Wukitch. Plasma wave simulation based on a versatile finite element method solver. Physics of Plasmas, 17(5):056119, 2010.

[11] J. Jacquot, D. Milanesio, L. Colas, Y. Corre, M. Goniche, J. Gunn, S. Heuraux, and M. Kubič. Radio-frequency sheaths physics: Experimental characterization on tore supra and related self-consistent modeling. Physics of Plasmas, 21(6):061509, 2014.

[12] W. Tierens, J. Jacquot, V. Bobkov, J.M. Noterdaeme, L. Colas, and The ASDEX Upgrade Team. Nonlinear plasma sheath potential in the ASDEX Upgrade 3strap antenna: a parameter scan. Nuclear Fusion, 57(11):116034, 2017.

[13] W. Tierens, J. Jacquot, W. Zhang, J.M. Noterdaeme, V. Bobkov, and L. Colas. 3-dimensional density profiles 

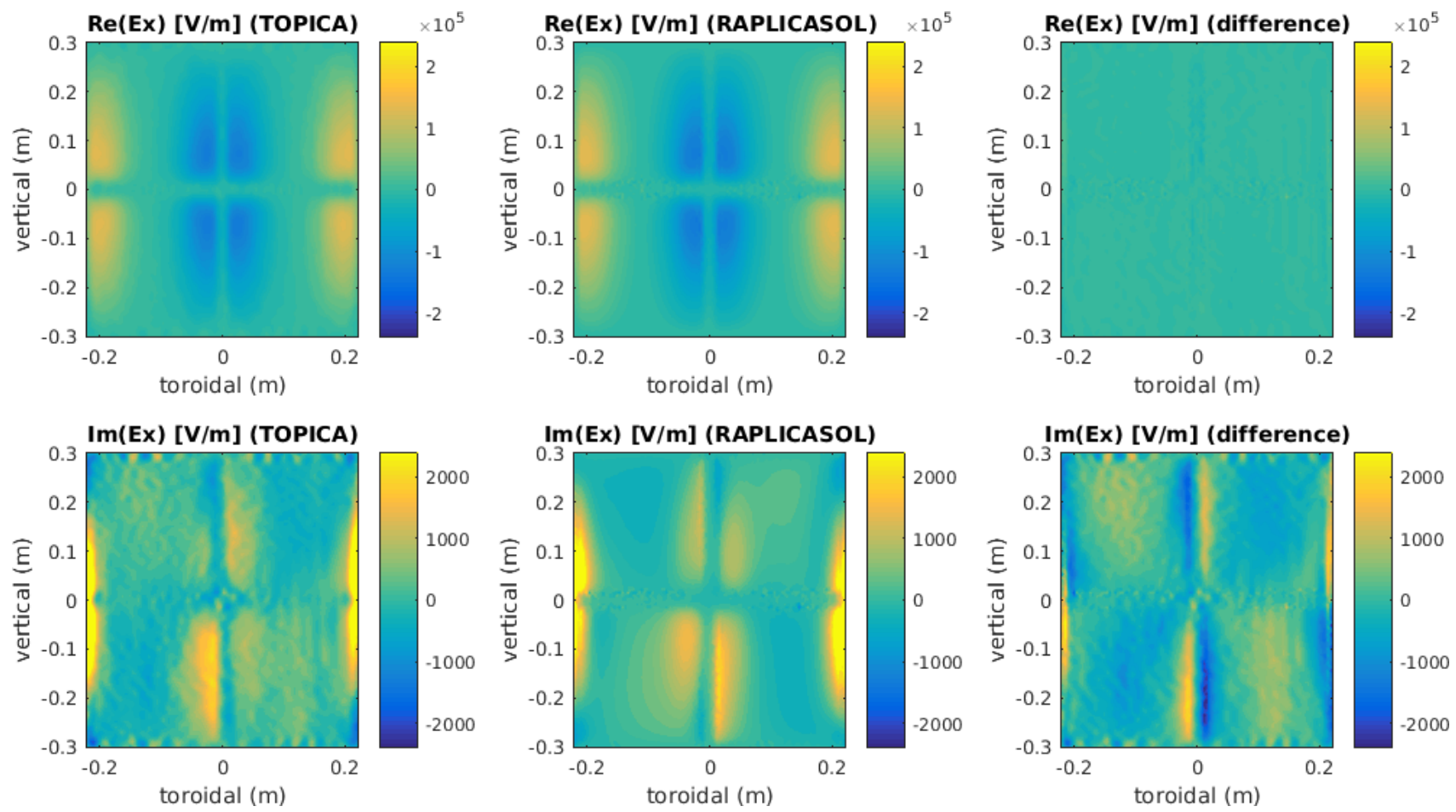

Figure 25. Real and imaginary part of $E_{x}$ at the aperture of the 4-strap WEST-like antenna, with dipole excitation (1MW total coupled power), calculated by RAPLICASOL and TOPICA.
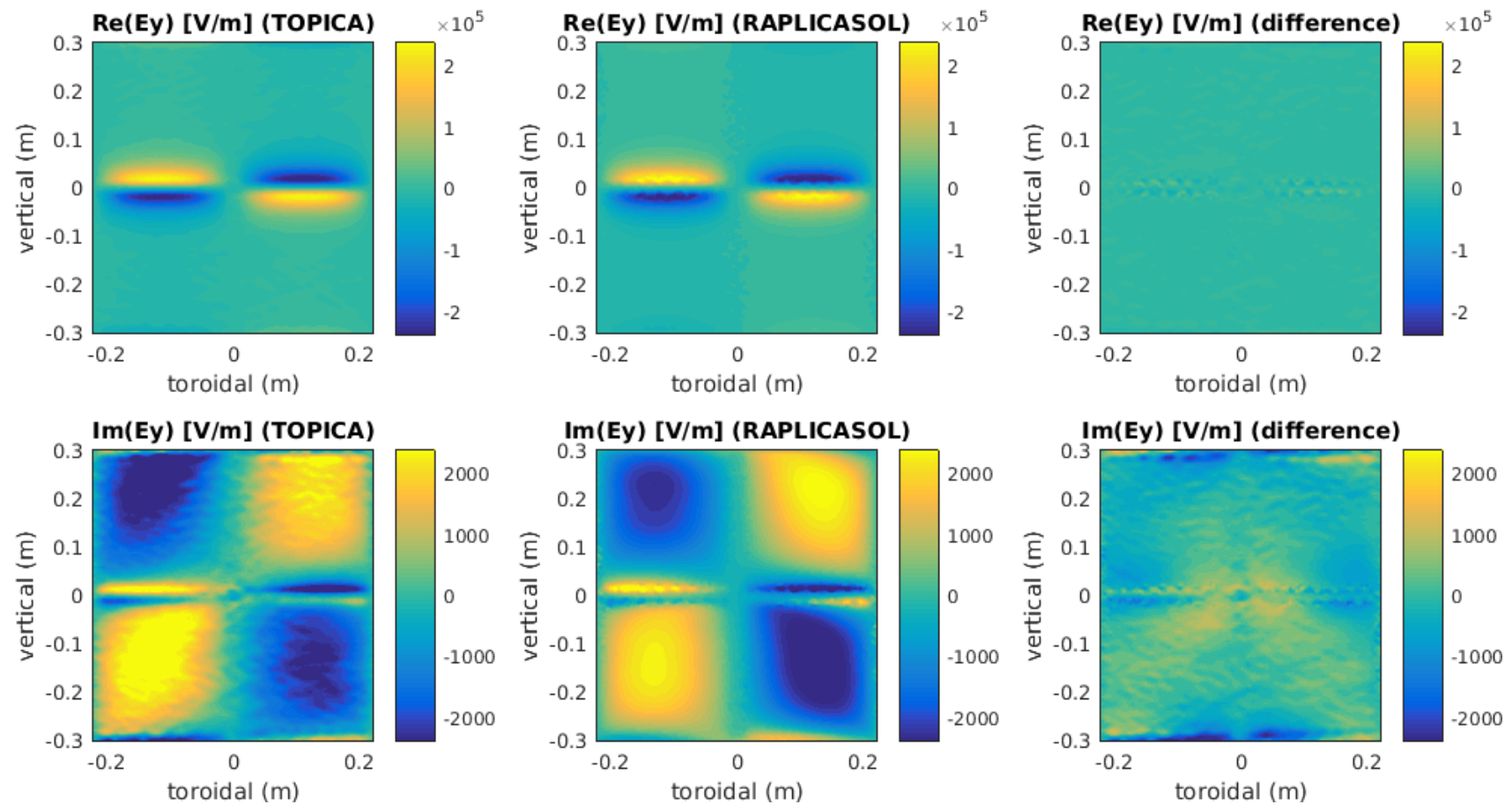

Figure 26. Real and imaginary part of $E_{y}$ at the aperture of the 4-strap WEST-like antenna, with dipole excitation (1MW total coupled power), calculated by RAPLICASOL and TOPICA. 

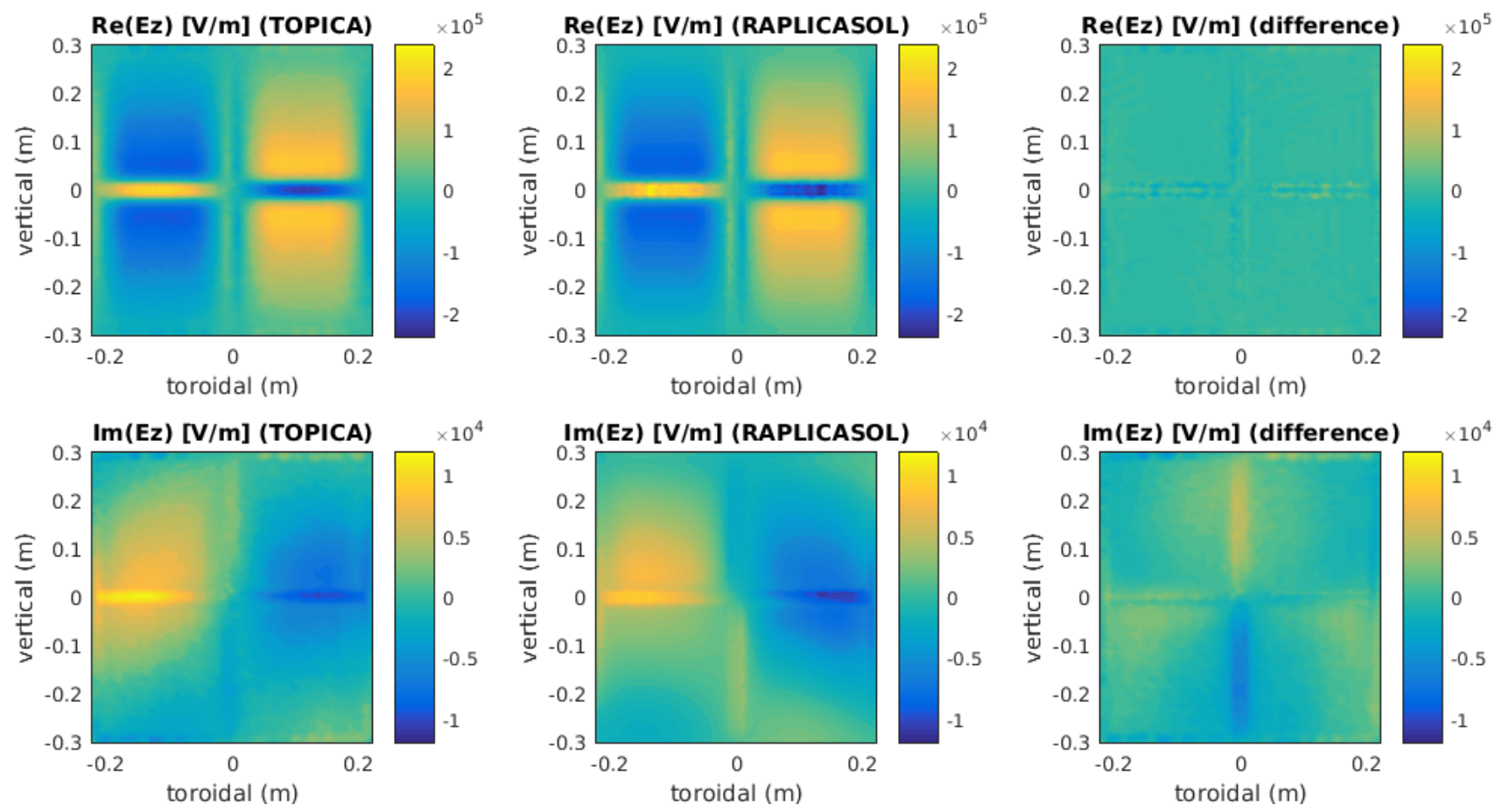

Figure 27. Real and imaginary part of $E_{z}$ at the aperture of the 4-strap WEST-like antenna, with dipole excitation (1MW total coupled power), calculated by RAPLICASOL and TOPICA.

in edge plasma simulations for ICRF heating. In $E P J$ Web of Conferences, volume 157, page 03053. EDP Sciences, 2017.

[14] Thomas H Stix. Waves in plasmas. Springer Science \& Business Media, 1992.

[15] S. Shiraiwa, J. C. Wright, J. P. Lee, P. T. Bonoli, and $\mathrm{T}$. Kolev. Integration of core/edge plasmas in fullwave RF simulation. In Preprint: 2016 IAEA Fusion Energy Conference, Kyoto [TH/P4-27], 2016.

[16] S. Shiraiwa, J.C. Wright, J.P. Lee, and P.T. Bonoli. HISTORIC: extending core ICRF wave simulation to include realistic SOL plasmas. Nuclear Fusion, 57(8):086048, 2017.

[17] https://www.cineca.it/.

[18] M. Campos Pinto and B. Després. Constructive formulations of resonant Maxwell's equations. SIAM Journal on Mathematical Analysis, 49(5):3637-3670, 2017.

[19] S. Rao, D. Wilton, and A. Glisson. Electromagnetic scattering by surfaces of arbitrary shape. IEEE Transactions on Antennas and Propagation, 30(3):409418, May 1982.

[20] http://www.netlib.org/lapack/.

[21] Y. Saad and M. Schultz. GMRES: A generalized minimal residual algorithm for solving nonsymmetric linear systems. SIAM Journal on scientific and statistical computing, 7(3):856-869, 1986.

[22] G. Haase, M. Kuhn, and U. Langer. Parallel multigrid 3D Maxwell solvers. Parallel computing, 27(6):761-775, 2001.

[23] R. Hiptmair. Multigrid method for Maxwell's equations. SIAM Journal on Numerical Analysis, 36(1):204-225, 1998.

[24] R. Bilato, M. Brambilla, D.A. Hartmann, and A. Parisot. Influence of an evanescence layer in front of the antenna on the coupling efficiency of ion cyclotron waves. Nuclear fusion, 45(2):L5, 2005.

[25] R. Fischer, C.J. Fuchs, B. Kurzan, W. Suttrop, E. Wolfrum, and ASDEX Upgrade Team. Integrated data analysis of profile diagnostics at ASDEX Upgrade. Fusion science and technology, 58(2):675-684, 2010.

[26] D. Milanesio, S. Ceccuzzi, R. Maggiora, and V. Bobkov. Analysis of the impact of antenna and plasma models on rf potentials evaluation. AIP Conference Proceedings, 1406(1):81-84, 2011.

[27] D. Milanesio, R. Maggiora, and V. Bobkov. Analysis of the ASDEX Upgrade 3-strap antenna with TOPICA code: Curved vs. flat 3D geometry. In EPJ Web of Conferences, volume 157, page 03034. EDP Sciences, 2017.

[28] J.M. Noterdaeme, M. Söll, J. Baeumler, G. Becker, H.S. Bosch, M. Brambilla, F. Braun, A. Brocken, A. Eberhagen, R. Fritsch, et al. The role of the faraday screen in ICRF antennae: Comparison of an optically open and optically closed screen in ASDEX. Technical report, 1986.

[29] I. Monakhov, P. Jacquet, T. Blackman, V. Bobkov, P. Dumortier, W. Helou, E. Lerche, K. Kirov, D. Milanesio, R. Maggiora, C. Noble, and JET Contributors. ICRH antenna S-matrix measurements and plasma coupling characterisation at JET. Nuclear Fusion, 58(4):046012, 2018.

[30] W. Helou, L. Colas, J. Hillairet, D. Milanesio, P. Mollard, A. Argouarch, G. Berger-By, J.-M. Bernard, Z. Chen, J.-M. Delaplanche, et al. Radio-frequency electrical design of the WEST long pulse and load-resilient ICRH launchers. Fusion Engineering and Design, 96:473-476, 2015.

[31] W. Helou, P. Dumortier, Frédéric Durodié, M. Goniche, J. Hillairet, P. Mollard, G. Berger-By, J.-M. Bernard, L. Colas, G. Lombard, et al. Sidon: A simulator of radiofrequency networks. application to west icrf launchers. In AIP Conference Proceedings, volume 1689, page 070004. AIP Publishing, 2015.

[32] F. Durodié, P. Dumortier, W. Helou, A. Křivská, E. Lerche, 
and JET Contributors. Circuit model of the iter-like antenna for jet and simulation of its control algorithms. In AIP Conference Proceedings, volume 1689, page 070013. AIP Publishing, 2015.

[33] W. Helou, P. Dumortier, F. Durodié, M. Goniche, J. Hillairet, G. Berger-By, J.-M. Bernard, L. Colas, R. Maggiora, R. Magne, et al. Array antennas in magnetic nuclear fusion and their modelling at the ion cyclotron resonance frequency. In Antennas and Propagation (EuCAP), 2015 9th European Conference on, pages 1-5. IEEE, 2015.

[34] https://www.ansys.com/products/electronics/ansys-hfss.

[35] C. C. Klepper, R. C. Isler, J. Hillairet, E. H. Martin, L. Colas, A. Ekedahl, M. Goniche, J. H. Harris, D. L. Hillis, S. Panayotis, B. Pegourié, Ph. Lotte, G. Colledani, V. Martin, and Tore Supra Lower Hybrid Systems Technical Team. Dynamic stark spectroscopic measurements of microwave electric fields inside the plasma near a high-power antenna. Phys. Rev. Lett., 110:215005, May 2013. 